\title{
Uma reflexão a respeito da resiliência regional evolucionária para regiões periféricas
}

\author{
Alexandre Aloys Matte Júnior - Doutorando do PPG \\ em Economia da Unisinos;
}

Dra. Janaína Ruffoni Trez - Docente do PPG em

Economia da Unisinos;

Dra. Gisele Spricigo - Docente do PPG em Economia

da Unisinos

\begin{abstract}
resumo: Este artigo apresenta uma revisão bibliográfica de contribuições de pesquisas sobre a perspectiva evolucionária da resiliência regional, buscando contribuições do tema para regiões periféricas. Foram selecionadas 35 publicações nas bases de Periódicos CAPES, Circle (Lund University) e IDEAS RePEC. Identificou-se que o conceito de resiliência regional vai além da capacidade de uma região de responder a choques econômicos, devendo ser capaz de sustentar o desenvolvimento no longo prazo, criando novas trajetórias de crescimento para compensar processos de estagnação e declínio econômico. Ressalta-se o destaque que "inovação" e "conhecimento" possuem na discussão de resiliência regional evolucionária. Também foram analisados estudos empíricos sobre resiliência em diferentes regiões, dando-se ênfase a países emergentes, em que casos a respeito do Brasil, Chile, Indonésia e Turquia auxiliam na identificação de que o conceito precisa ser mais explorado para além do continente europeu.
\end{abstract}

palavras-chave: Resiliência Regional Evolucionária; Inovação; Países Emergentes; Revisão da Literatura.

Código JEL: O3; R11

Área Temática: Área 4 - Redes e sistemas urbanos, regionais e nacionais; 4.2 - Economias Regionais e Urbanas 


\section{Introdução}

No campo da geografia econômica, o conceito de resiliência foi adaptado do estudo de sistemas ecológicos e outros campos científicos relacionados à compreensão de sistemas socioeconômicos geograficamente incorporados, sendo utilizado principalmente em debates sobre desenvolvimento econômico de regiões. Silva e Exterckoter (2016) lembram que resiliência é um conceito muito utilizado nas ciências ecológicas, onde se relaciona à capacidade de um ecossistema de resistir a choques externos, de se adaptar e de responder a eles, ao invés de sucumbir. Nesse sentido, a resiliência reflete a ideia de adaptabilidade e de sobrevivência de um sistema perante choques externos.

Assim, entende-se por resiliência a capacidade permanente de um território de conceber e implantar novos recursos e capacidades, que lhe permitam adaptar-se favoravelmente à dinâmica de transformação, impulsionada pelas mudanças do ambiente. Em suma, regiões resilientes seriam aquelas que se adaptam de forma mais rápida à mudança, que são menos vulneráveis a choques externos e turbulências e, também, que possam responder mais rapidamente às crises ou evitar dificuldades socioeconômicas. Como frisa Gonçalves (2017), uma região (ou comunidade) "resiliente amplia oportunidades para todos os grupos etários e sociais, estabelece e consolida uma rede de conectividades e internaliza, na sua matriz socioeconômica, condições de aprendizagem que permitem evitar ou inovar a partir de quadros de tensão" (p. 383). Também, Schmidt e Zen (2010) contribuem afirmando que a ideia de resiliência é de manutenção do sucesso econômico, através de um longo período, adaptando o sistema às necessidades que cada distúrbio exige. Dessa forma, a resiliência não se restringe à resposta a choques e a dificuldades pontuais, mas se caracteriza por ser um processo contínuo. Nesse sentido, Boschma (2015) conceitua a resiliência não apenas como a capacidade de uma região para acomodar choques, mas a capacidade de longo prazo das regiões desenvolverem novas trajetórias de crescimento, numa perspectiva de evolução.

Há um interesse crescente, de acordo com Boschma (2015), em uma abordagem evolucionária da resiliência regional, que foque mais na evolução de longo prazo de regiões e de sua capacidade de adaptarem-se e reconfigurarem suas estruturas industriais, tecnológicas e institucionais, em um sistema econômico permanentemente em evolução, onde a resiliência é considerada um processo contínuo e não uma recuperação para um estado de equilíbrio estável (seja este pré-existente ou totalmente novo) (Simmie; Martin, 2010). Porém, apesar da importância da perspectiva apresentada, Martin (2012) argumenta que a capacidade adaptativa de longo prazo das regiões é pouco pesquisada. Antonietti e Boschma (2018) citam que os efeitos do capital social na inovação regional em tempos de crise, ainda são relativamente inexplorados, tanto em termos teóricos quanto empíricos. Por fim, observa-se a constatação de que, relativamente, existem poucos trabalhos que exploram o conceito de resiliência regional na perspectiva evolucionária em regiões de países emergentes ou periféricos. Em geral, os estudos identificados se concentram em regiões europeias ou norte-americanas e discutem, por exemplo, a resiliência na União Europeia no período pós-crise de 2008, a emergência de novas indústrias e a especialização inteligente na UE.

Dessa maneira, esse artigo tem como objetivo revisar, de forma não exaustiva, algumas contribuições teóricas e empíricas advindas de pesquisas focadas na perspectiva evolucionária da resiliência regional, buscando principalmente possíveis contribuições do tema para países emergentes. Nesse sentido, o problema de pesquisa a ser respondido constitui-se em: "Qual é a contribuição dos trabalhos selecionados para o entendimento das principais características (forma com que a resiliência é medida, conceito de região utilizado, entre outros) do conceito de resiliência regional evolucionária e de sua aplicação em regiões de países emergentes?”. Para tanto, foi feita uma revisão de uma literatura acadêmica selecionada. Para a realização deste trabalho, foram consultadas as bases de publicações do Circle (Centre for Innovation, Research and Competence in the learning economy - Lund University), do Periódicos CAPES e do IDEAS RePEc. Optou-se por estas bases pelo foco de pesquisas do Circle e a abrangência da base IDEAS RePEc, contando com autores seminais sobre temáticas relacionadas à resiliência regional e ao desenvolvimento econômico. Já a base de Periódicos CAPES foi selecionada pelo fato de contar com volume de materiais desenvolvidos por pesquisadores do Brasil e arredores.

O restante deste artigo está organizado da seguinte forma: a seção 2 apresenta os procedimentos metodológicos da pesquisa e os achados em termos de artigos selecionados para análise; na seção 3 são apresentados e discutidos os resultados; e a seção 4 conclui o estudo.

\section{Procedimentos metodológicos}

Para a seleção da bibliografia utilizada no trabalho, foram adotados os seguintes critérios: i) conter as seguintes expressões em português, inglês ou espanhol "resiliência regional, resiliência regional 
evolucionária, país emergente resiliente, país em desenvolvimento resiliente ${ }^{1 "}$ no título ou no resumo do trabalho; e ii) ser trabalho científico das áreas de Economia, Negócios e/ou Geografia e; iii) ter sido publicado entre 2010 a 2020. Esses critérios foram aplicados nas três bases de dados utilizadas, conforme já mencionado: (i) Base de publicações do Circle (Centre for Innovation, Research and Competence in the learning economy - Lund University), (ii) Periódicos CAPES e (iii) Base IDEAS RePEc.

Em um primeiro momento foram selecionados 3.200 trabalhos. Na sequência, foi aplicado o filtro "Mais Relevantes" em cada base de dados, levando em conta os artigos mais acessados e, posteriormente, foram analisados os resumos dos 150 artigos resultantes, avaliando-se a convergência com a temática e com o objetivo do trabalho. Nessa etapa, foram selecionados 110 trabalhos. Posteriormente, foram descartados os trabalhos que não apresentavam conteúdos relevantes ao objetivo da pesquisa e, desta forma, restaram 35 publicações para a realização deste estudo.

A partir da leitura e análise dos trabalhos selecionados, foi elaborado um banco de dados a fim de organizar as seguintes informações: (i) ano; (ii) título; (iii) autores; (iv) palavras-chave; (v) periódico ou base de dados; (vi) local de origem da publicação; (vii)) área de publicação. Os 35 artigos foram analisados considerando-se as seguintes questões (i) caracterização do termo resiliência regional, buscando identificar de que forma o termo foi abordado e como foi mensurado; (ii) caracterização específica de resiliência regional evolucionária e explicação a respeito do seu surgimento e evolução conceitual e; (iii) considerações sobre os estudos empíricos e suas principais conclusões. O Quadro 1 apresentado na próxima seção, sintetiza os achados.

\section{Descrição e análise}

Uma síntese das 35 publicações analisadas é apresentada no Quadro 1. A lista dos estudos está organizada por ordem cronológica da data publicada e, para cada publicação, informa os autores, o método empregado no estudo, o período de tempo considerado no estudo, a região analisada e os principais resultados obtidos.

No Quadro 1, pode-se notar uma concentração das publicações nos anos de 2017 a 2020, correspondendo a $37,1 \%$ dos trabalhos selecionados, indicando que estudos sobre resiliência regional continuam sendo realizados. Importante também frisar a concentração de trabalhos no ano de 2010 que representam $14,3 \%$ do total. Os estudos apontam para o uso de métodos variados, como a condução de estudo de caso, realização de entrevistas com atores regionais, estudos quantitativos e utilização de dados secundários, como dados relativos ao emprego/desemprego, renda, PIB, VAB e outros. Os exemplos de estudos empíricos conduzidos auxiliam na compreensão de possibilidades e de escolhas que podem ser feitas pelo pesquisador, uma vez que diferentes territórios são analisados pelas lentes da resiliência regional.

\begin{tabular}{|c|c|c|c|c|}
\hline Ano & Autor/Autores & $\begin{array}{l}\text { Método e tipos de } \\
\text { dados utilizados }\end{array}$ & $\begin{array}{l}\text { Período, região ou } \\
\text { setor estudado }\end{array}$ & Principais resultados \\
\hline 2010 & $\begin{array}{l}\text { Dawley, Stuart; } \\
\text { Pike, Andy; } \\
\text { Tomaney }\end{array}$ & Estudo de caso & $\begin{array}{l}2001-2008 \\
\text { Nordeste da } \\
\text { Inglaterra e setor } \\
\text { de energia } \\
\text { renovável }\end{array}$ & $\begin{array}{l}\text { Demonstra o papel duradouro da intervenção política no } \\
\text { estímulo à mudança e na construção da resiliência nas } \\
\text { regiões periféricas estudadas. }\end{array}$ \\
\hline 2010 & Hassink & Revisão teórica & Não se aplica & $\begin{array}{l}\text { O artigo visa avaliar criticamente se a resiliência } \\
\text { regional contribui para o entendimento da } \\
\text { adaptabilidade econômica regional, em particular, e sua } \\
\text { contribuição potencial para a geografia econômica } \\
\text { evolucionária em geral. Conclui que, devido a três } \\
\text { deficiências principais, sua contribuição é relativamente } \\
\text { limitada. Essas deficiências estão relacionadas à: a) foco } \\
\text { no equilíbrio e multi-equilíbrio; b) a negligência do } \\
\text { estado, instituições e políticas em vários níveis espaciais } \\
\text { e; c) a negligência da cultura e dos fatores sociais que } \\
\text { afetam a adaptabilidade. }\end{array}$ \\
\hline 2010 & $\begin{array}{l}\text { Pendall, Rolf; } \\
\text { Foster, Kathryn } \\
\text { A. Cowell }\end{array}$ & Revisão teórica & Não se aplica & $\begin{array}{l}\text { Autores pesquisaram literaturas de diferentes áreas do } \\
\text { conhecimento, como psicologia, ecologia, geografia, } \\
\text { ciência política e economia para compreender como a } \\
\text { resiliência é explorada. Concluem que, embora a }\end{array}$ \\
\hline
\end{tabular}

\footnotetext{
${ }^{1}$ Esses termos utilizados em inglês e espanhol foram, respectivamente, "regional resilience, evolutionary regional resilience, emerging country, developing country" e "resiliencia regional, resiliencia regional evolutiva, país emergente resiliente, país en desarrollo resiliente".
} 


\begin{tabular}{|c|c|c|c|c|}
\hline & & & & $\begin{array}{l}\text { metáfora da resiliência represente o perigo de } \\
\text { imprecisão e necessite de uma especificação cuidadosa } \\
\text { dos limites de espaço e tempo no estudo dos fenômenos } \\
\text { de resiliência, ela se mostra útil para evidenciar } \\
\text { estratégias, alternativas e processos de mudança e } \\
\text { desenvolvimento regional. }\end{array}$ \\
\hline 2010 & $\begin{array}{l}\text { Pike, Andy; } \\
\text { Dawley, Stuart; } \\
\text { Tomaney }\end{array}$ & Revisão teórica & Não se aplica & $\begin{array}{l}\text { Objetivou contribuir para a compreensão e explicação } \\
\text { da resiliência de regiões. Os conceitos de adaptação e } \\
\text { adaptabilidade são desenvolvidos em uma estrutura } \\
\text { baseada em agentes, mecanismos e lugares. }\end{array}$ \\
\hline 2010 & $\begin{array}{c}\text { Simmie, James; } \\
\text { Martin }\end{array}$ & $\begin{array}{l}\text { Estudo de caso } \\
\text { Utiliza dados } \\
\text { históricos e } \\
\text { quantitativos } \\
\text { (empregos, novas } \\
\text { empresas, ...) }\end{array}$ & $\begin{array}{l}1960-2009 \\
\text { Cambridge e } \\
\text { Swansea - } \\
\text { Reino Unido }\end{array}$ & $\begin{array}{l}\text { Fontes endógenas de novos conhecimentos combinadas } \\
\text { com decisões conscientes e empreendedoras orientadas } \\
\text { pelo mercado podem estar entre os fatores-chave para } \\
\text { entender a resiliência econômica regional. A facilitação } \\
\text { de ambientes institucionais também é significativa. Por } \\
\text { outro lado, onde as fontes de conhecimento existentes } \\
\text { estão presas em tecnologias estáveis, a capacidade } \\
\text { adaptativa de longo prazo e a resiliência tendem a } \\
\text { diminuir. A histerese institucional e as culturas } \\
\text { imutáveis também podem contribuir para a falta de } \\
\text { resiliência. }\end{array}$ \\
\hline 2011 & $\begin{array}{l}\text { Harrison, Ann; } \\
\text { Sepúlveda }\end{array}$ & $\begin{array}{l}\text { Estudo de caso } \\
\text { Análise de dados } \\
\text { secundários (PIB, } \\
\text { desigualdades } \\
\text { internas, média de } \\
\text { salários da } \\
\text { população, ...) } \\
\end{array}$ & $\begin{array}{l}\text { Dados de antes e } \\
\text { depois da crise de } \\
2008 \\
\text { Variados países em } \\
\text { desenvolvimento }\end{array}$ & $\begin{array}{l}\text { Apresenta evidências empíricas do crescimento dos } \\
\text { países em desenvolvimento antes e depois da crise } \\
\text { econômica e financeira de 2008-2009, e de como esse } \\
\text { melhor desempenho levou a uma mudança no cenário } \\
\text { econômico global no qual os países em } \\
\text { desenvolvimento estão tomando o centro da situação, à } \\
\text { medida que vários polos de crescimento emergem. }\end{array}$ \\
\hline 2011 & $\begin{array}{l}\text { Neffke, Frank; } \\
\text { Henning, } \\
\text { Martin; } \\
\text { Boschma, Ron. }\end{array}$ & $\begin{array}{l}\text { Estudo de caso } \\
\text { Uso de dados } \\
\text { secundários e } \\
\text { indicador de } \\
\text { relação tecnológica } \\
\text { entre indústrias } \\
\text { manufatureiras }\end{array}$ & $\begin{array}{c}1969 \text { a } 2002 \\
70 \text { regiões suecas - } \\
174 \text { diferentes } \\
\text { indústrias } \\
\text { manufatureiras }\end{array}$ & $\begin{array}{l}\text { A evolução a longo prazo do cenário econômico na } \\
\text { Suécia está sujeita a fortes dependências de trajetórias. } \\
\text { As indústrias que estavam tecnologicamente } \\
\text { relacionadas com as indústrias pré-existentes em uma } \\
\text { região tinham maior probabilidade de emergirem em } \\
\text { determinada região do que as tecnologicamente não } \\
\text { relacionadas. Também, os perfis industriais das regiões } \\
\text { suecas apresentaram alto grau de coesão tecnológica. } \\
\text { Apesar de mudanças estruturais substanciais, essa } \\
\text { coesão foi persistente ao longo do tempo. }\end{array}$ \\
\hline 2012 & $\begin{array}{c}\text { Didier, Tatiana; } \\
\text { Hevia, } \\
\text { Constantino; } \\
\text { Schmukler, } \\
\text { Sergio L. }\end{array}$ & $\begin{array}{l}\text { Estudo de caso } \\
\text { Uso de dados } \\
\text { secundários (PIB, } \\
\text { produção } \\
\text { industrial, renda, } \\
\text {...) }\end{array}$ & $\begin{array}{c}\text { Dados de antes e } \\
\text { depois da crise de } \\
2008 \\
\text { Diferentes } \\
\text { economias } \\
\text { emergentes de } \\
\text { diferentes } \\
\text { continentes }\end{array}$ & $\begin{array}{l}\text { As economias emergentes sofreram colapsos de } \\
\text { crescimento (em relação aos níveis pré-crise) } \\
\text { comparáveis aos experimentados pelas economias } \\
\text { desenvolvidas, mesmo quando continuaram crescendo. } \\
\text { Depois, a maioria das economias retornou às suas taxas } \\
\text { de crescimento pré-crise. As economias emergentes } \\
\text { foram mais resilientes durante a crise global do que } \\
\text { durante as crises passadas. As economias emergentes } \\
\text { não caíram mais do que as economias desenvolvidas } \\
\text { durante a crise global e foram capazes de conduzir } \\
\text { políticas contracíclicas, tornando-se, assim, semelhantes } \\
\text { às economias desenvolvidas. }\end{array}$ \\
\hline 2012 & Martin & $\begin{array}{l}\text { Estudo de caso } \\
\text { Análises dados } \\
\text { secundários } \\
\text { (emprego e renda } \\
\text { por região em } \\
\text { períodos antes e } \\
\text { depois de choques) }\end{array}$ & $\begin{array}{l}1979-2010 \\
\text { Reino Unido - } \\
\text { Regiões NUTS } 1 \\
\text { (North East, North } \\
\text { West, Yorkshire } \\
\text { and the Humber, } \\
\text { East Midlands, } \\
\text { West Midlands, } \\
\text { East of England, } \\
\text { London, South } \\
\text { East e South West) }\end{array}$ & $\begin{array}{l}\text { Diferentes regiões reagiram de forma muito diferente } \\
\text { aos principais choques ao longo do período analisado. } \\
\text { Em termos de resistência à recessão, as economias } \\
\text { regionais analisadas parecem apresentar diferentes graus } \\
\text { de resiliência. Em algumas das regiões mais afetadas, a } \\
\text { dramática queda no emprego produtivo foi agravada por } \\
\text { uma queda, ainda que significativamente menos grave, } \\
\text { nos empregos de serviço, enquanto em algumas das } \\
\text { regiões em que o impacto da recessão no setor } \\
\text { produtivo foi menos acentuado (Sudeste, Leste, } \\
\text { Sudoeste), o emprego de serviços aumentou. Os } \\
\text { achados empíricos indicam que a resiliência regional à } \\
\text { recessão pode variar e mudar ao longo do tempo. A } \\
\text { resiliência não é uma característica estática de uma } \\
\text { economia, mas um processo dinâmico, influenciado } \\
\text { tanto pelo impacto de grandes choques quanto pela } \\
\text { contínua inquietação da mudança econômica estrutural e }\end{array}$ \\
\hline
\end{tabular}




\begin{tabular}{|c|c|c|c|c|}
\hline & & & & da adaptação. \\
\hline 2012 & $\begin{array}{l}\text { Navarro- } \\
\text { Espigares, José } \\
\text { Luis; Martín- } \\
\text { Segura, José } \\
\text { Aureliano; } \\
\text { Hernández- } \\
\text { Torres }\end{array}$ & $\begin{array}{l}\text { Estudo de caso } \\
\text { Análise de dados } \\
\text { secundários (VAB } \\
\text { e emprego); } \\
\text { análise descritiva, } \\
\text { utilizando } \\
\text { regressão de série } \\
\text { temporal }\end{array}$ & $\begin{array}{l}1986-2009 \\
17 \text { regiões } \\
\text { espanholas }\end{array}$ & $\begin{array}{l}\text { O estudo teve a intenção de verificar se o setor de } \\
\text { serviços na estrutura produtiva de regiões espanholas } \\
\text { possui influência sobre sua reação às crises econômicas. } \\
\text { Para tanto, utilizaram de VAB e emprego de } 17 \text { regiões } \\
\text { espanholas durante o período 1986-2009. Concluem } \\
\text { que, tanto na crise econômica de } 1992 \text { como na de } 2008 \text {, } \\
\text { as regiões intensivas em atividades relacionadas à } \\
\text { serviços demonstraram maior resiliência, possuindo } \\
\text { maior resistência à perda de VAB e empregos. }\end{array}$ \\
\hline 2013 & $\begin{array}{l}\text { González- } \\
\text { Muzzio }\end{array}$ & $\begin{array}{l}\text { Estudo de caso } \\
\text { Dados } \\
\text { quantitativos } \\
\text { e qualitativos; e } \\
\text { realização de } \\
\text { entrevistas. }\end{array}$ & $\begin{array}{l}2013 \\
\text { San Pedro de La } \\
\text { Paz - Área } \\
\text { Metropolitana de } \\
\text { Concepción } \\
\text { (AMC) - Chile }\end{array}$ & $\begin{array}{l}\text { Os resultados indicam que existem fatores sociais que } \\
\text { possuem a capacidade de modificar fortemente a } \\
\text { resiliência de uma cidade e sua comunidade. Os autores } \\
\text { focaram em como os terremotos ocorridos na região de } \\
\text { San Pedro de La Paz provocaram a articulação e } \\
\text { comportamento coletivo da população, contribuindo } \\
\text { positivamente para melhorar a resiliência adaptativa da } \\
\text { comunidade. Estes fatores devem ser considerados no } \\
\text { planejamento e / ou reconstrução de cidades com } \\
\text { maiores níveis de resiliência. }\end{array}$ \\
\hline 2014 & $\begin{array}{l}\text { Crespo, Joan; } \\
\text { Suire, Raphael; } \\
\text { Vicente, } \\
\text { Jerome. }\end{array}$ & $\begin{array}{l}\text { Revisão de } \\
\text { literatura }\end{array}$ & Não se aplica & $\begin{array}{l}\text { O estudo conclui que políticas direcionadas à resiliência } \\
\text { regional devem se concentrar em diagnóstico regional } \\
\text { ex-ante e proporcionar intervenções direcionadas às } \\
\text { características que estejam ausentes na rede ao invés de } \\
\text { fomentar políticas que não estejam alinhadas com o que } \\
\text { a região realmente necessita desenvolver. }\end{array}$ \\
\hline 2014 & $\begin{array}{l}\text { Pitteri, Sirlei; } \\
\text { Bresciani }\end{array}$ & $\begin{array}{l}\text { Revisão teórica } \\
\text { Estudo de caso }\end{array}$ & $\begin{array}{l}1983-2008 \\
\text { Polo Industrial de } \\
\text { Cubatão, SP }\end{array}$ & $\begin{array}{l}\text { O estudo analisou como uma região conseguiu reverter } \\
\text { uma situação iminente de desindustrialização por meio } \\
\text { de esforços conjuntos. Com relação aos aspectos } \\
\text { econômicos e aos objetivos propostos no Plano de Ação } \\
\text { para a Recuperação Ambiental, é possível afirmar que } \\
\text { ocorreu uma transformação regional com desempenho } \\
\text { superior à situação anterior ao choque dos primeiros } \\
\text { anos da década de 1980, quando a região sofreu com } \\
\text { graves impactos ambientais proporcionados pelas } \\
\text { empresas locais. }\end{array}$ \\
\hline 2014 & Wink & $\begin{array}{l}\text { Revisão teórica } \\
\text { Estudo de caso } \\
\text { Análise de dados } \\
\text { secundários (PIB, } \\
\text { VAB, emprego e } \\
\text { desemprego) }\end{array}$ & Não se aplica & $\begin{array}{l}\text { O estudo descreve a experiência em Grand Forks } \\
\text { (EUA), onde dados quantitativos como o PIB e nível de } \\
\text { emprego não mostraram resiliência às crises, mas as } \\
\text { pessoas da área expressaram satisfação com o } \\
\text { desenvolvimento na região. Citam que políticas devem } \\
\text { apoiar ligações entre indústrias até então não } \\
\text { relacionadas. Uma alta intensidade de conexões entre } \\
\text { diferentes atores envolvidos com determinado tipo de } \\
\text { atividade tende a aumentar a produtividade das } \\
\text { colaborações e poderia ajudar a encontrar soluções } \\
\text { comuns em casos de choques externos. Essas conexões } \\
\text { intensivas também podem causar risco de lock-in, a } \\
\text { menos que sejam modificadas por atores externos que } \\
\text { tenham a capacidade de apoiar a diversificação ou criar } \\
\text { opções adicionais para a região. }\end{array}$ \\
\hline 2015 & Boschma, Ron. & $\begin{array}{l}\text { Revisão de } \\
\text { literatura }\end{array}$ & Não se aplica & $\begin{array}{l}\text { Os conceitos de variedade relacionada e não-relacionada } \\
\text { são importantes no estudo e são entendidos como: a) } \\
\text { variedade relacionada - aumenta o potencial de } \\
\text { recombinação de uma região, e fornece recursos locais } \\
\text { (relacionados) nos quais novas trajetórias de } \\
\text { crescimento podem ser construídas e desenvolvidas e; } \\
\text { b) variedade não-relacionada - consiste num alto nível } \\
\text { de diversificação sem vínculos com as indústrias da } \\
\text { região, diminuindo a vulnerabilidade a choques } \\
\text { externos, pois há menos risco de o sofrimento da } \\
\text { economia regional devido a efeitos contagiosos por } \\
\text { meio de vínculos intersetoriais. }\end{array}$ \\
\hline 2015 & $\begin{array}{l}\text { Courvisanos, } \\
\text { Jerry; Jain, } \\
\text { Ameeta; } \\
\text { Mardaneh, }\end{array}$ & $\begin{array}{l}\text { Estudo de caso } \\
\text { Dados secundários } \\
\text { (dados de emprego } \\
\text { e mudança de }\end{array}$ & $\begin{array}{l}2001-2011 \\
558 \text { áreas do } \\
\text { governo local } \\
\text { (LGAs) na }\end{array}$ & $\begin{array}{l}\text { Avaliam que o desenvolvimento da adaptabilidade } \\
\text { através de amplas estratégias de resiliência surgem de } \\
\text { um entendimento profundo de mecanismos e causas que } \\
\text { devem ser identificadas de forma prévia por policy- }\end{array}$ \\
\hline
\end{tabular}




\begin{tabular}{|c|c|c|c|c|}
\hline & Karim K. & $\begin{array}{l}\text { renda ao longo do } \\
\text { tempo) }\end{array}$ & Austrália & $\begin{array}{l}\text { makers, antes da definição de uma agenda. O trabalho } \\
\text { fornece evidências empíricas únicas, usando dados de } \\
2001 \text { a } 2011 \text { para um continente inteiro em oposição à } \\
\text { estudos de caso focados em uma única região. }\end{array}$ \\
\hline 2015 & Eraydin & $\begin{array}{c}\text { Estudo de caso } \\
\text { Testes } \\
\text { econométricos para } \\
\text { mapear os } \\
\text { diferentes níveis de } \\
\text { resiliência entre as } \\
\text { regiões } \\
.\end{array}$ & $\begin{array}{c}\text { 1978-2011 } \\
26 \text { Regiões da } \\
\text { Turquia }\end{array}$ & $\begin{array}{l}\text { Os achados da pesquisa auxiliam no entendimento dos } \\
\text { motivos pelos quais uma estratégia trabalhada em uma } \\
\text { região pode não trazer o mesmo resultado em outra. Em } \\
\text { vez de aplicar estratégias similares em diferentes } \\
\text { regiões, um ponto de partida mais adequado seria } \\
\text { entender por que uma determinada região pertence a } \\
\text { uma certa categoria de resiliência. Trazem quatro } \\
\text { categorias de classificação em relação à resiliência: } \\
\text { "Não-resiliente", "Resistente à choques", "Prosperando" } \\
\text { e "Resiliente-em transformação". }\end{array}$ \\
\hline 2015 & $\begin{array}{l}\text { Martin, Ron; } \\
\text { Sunley }\end{array}$ & $\begin{array}{l}\text { Revisão teórica } \\
\text { Discussões sobre } \\
\text { aplicabilidade do } \\
\text { conceito de } \\
\text { resiliência regional }\end{array}$ & Não se aplica & $\begin{array}{l}\text { A definição de resiliência proposta no estudo implica } \\
\text { um foco no crescimento de longo prazo de uma região, } \\
\text { bem como no desenvolvimento e consequente foco nos } \\
\text { indicadores de emprego, produção, bem-estar e renda } \\
\text { associadas a ele. Diferentes aspectos da economia de } \\
\text { uma região podem diferir em sua resistência e reação a } \\
\text { choques adversos. }\end{array}$ \\
\hline 2016 & Duschl & $\begin{array}{l}\text { Estudo de caso } \\
\text { Análise de } \\
\text { regressão aplicada } \\
\text { sobre base de } \\
\text { dados regionais } \\
\text { Dados do } \\
\text { crescimento do } \\
\text { emprego }\end{array}$ & $\begin{array}{l}2007-2010 \\
\text { Regiões da } \\
\text { Alemanha }\end{array}$ & $\begin{array}{l}\text { Resultados mostram que a turbulência é mais acentuada } \\
\text { em regiões com maior desempenho de crescimento } \\
\text { agregado, com uma força de trabalho altamente } \\
\text { qualificada e com mais variedade não-relacionada } \\
\text { (consistindo num alto nível de diversificação sem } \\
\text { vínculos entre as indústrias da região, diminuindo a } \\
\text { vulnerabilidade a choques externos) no portfólio } \\
\text { industrial. Nesse sentido, uma estrutura industrial } \\
\text { diversificada que fornece variedade não- relacionada, } \\
\text { bem como a presença de uma força de trabalho } \\
\text { qualificada, parece importante para tornar economias } \\
\text { regionais mais resistentes. O autor ressalta que, no } \\
\text { entrando, ainda não se tem clareza sobre como as } \\
\text { instituições podem acomodar, da melhor maneira } \\
\text { possível, a turbulência causada por choques pontuais ou } \\
\text { de longo prazo e traduzi-los em mudanças e novas } \\
\text { trajetórias de desenvolvimento. O autor também frisa } \\
\text { que a resiliência neste contexto pode ter consequências } \\
\text { negativas para alguns trabalhadores, que podem } \\
\text { enfrentar dificuldades para se reempregarem por causa } \\
\text { de suas habilidades individuais dentro dessas novas } \\
\text { trajetórias que tendem a ser desenvolvidas. }\end{array}$ \\
\hline 2016 & $\begin{array}{l}\text { Sensier, } \\
\text { Marianne; } \\
\text { Bristow, } \\
\text { Gillian; Healy }\end{array}$ & $\begin{array}{l}\text { Estudo de caso } \\
\text { Uso de dados } \\
\text { secundários } \\
\text { (nível de emprego } \\
\text { e PIB) }\end{array}$ & $\begin{array}{l}\text { 1990-2011 } \\
\text { Regiões de } 28 \\
\text { países da União } \\
\text { Europeia }\end{array}$ & $\begin{array}{l}\text { O trabalho realizou uma análise detalhada das } \\
\text { diferenças na amplitude e duração dos processos de } \\
\text { recuperação de choque em todas as regiões. Forneceu } \\
\text { meios para identificar quais economias eram resistentes } \\
\text { a um choque econômico. }\end{array}$ \\
\hline 2016 & $\begin{array}{l}\text { Sánchez- } \\
\text { Zamora, Pedro; } \\
\text { Gallardo- } \\
\text { Cobos, Rosa; } \\
\text { Delgado }\end{array}$ & Revisão teórica & Não se aplica & $\begin{array}{l}\text { A revisão procurou avançar na conceituação de } \\
\text { resiliência territorial e no seu vínculo com a análise da } \\
\text { dinâmica dos territórios rurais. A abordagem } \\
\text { metodológica a este conceito constituiu um desafio, } \\
\text { entre outros motivos, devido às poucas contribuições } \\
\text { empíricas. }\end{array}$ \\
\hline 2016 & $\begin{array}{l}\text { Exterckoter, } \\
\text { Rudinei Kock; } \\
\text { Pujol, Antoni } \\
\text { Francesc Tulla; } \\
\text { Silva, Clécio } \\
\text { Azevedo }\end{array}$ & $\begin{array}{c}\text { Revisão } \\
\text { sistemática de } \\
\text { literatura }\end{array}$ & Não se aplica & $\begin{array}{l}\text { A revisão mostra que o processo de migração do } \\
\text { conceito para as ciências sociais e econômicas é } \\
\text { complexo e contrasta com a premissa de equilíbrio } \\
\text { (comum às ciências biológicas e engenharia), em que a } \\
\text { ideia de resiliência reconhece a hipótese de que deve } \\
\text { haver uma capacidade de adaptação nos territórios, } \\
\text { especialmente nas regiões em contextos desfavoráveis. } \\
\text { Os resultados demonstram que o conceito de resiliência } \\
\text { já se tornou um importante instrumento para explicar as } \\
\text { diferenças na capacidade das regiões para ajuste } \\
\text { econômico em cenários desfavoráveis. }\end{array}$ \\
\hline 2017 & Evenhuis & Revisão teórica & Não se aplica & $\begin{array}{l}\text { Concluem que o que é particular sobre a resiliência } \\
\text { econômica regional é sua ênfase explícita em lidar com }\end{array}$ \\
\hline
\end{tabular}




\begin{tabular}{|c|c|c|c|c|}
\hline & & & & $\begin{array}{l}\text { interrupções e instabilidade. Os determinantes da } \\
\text { resiliência econômica regional podem ser } \\
\text { identificados pela vinculação de diferenças de } \\
\text { desempenho em relação à resistência e recuperação, a } \\
\text { diferentes características de várias economias regionais, } \\
\text { por exemplo estrutura econômica, habilidades, } \\
\text { inovação, renda média familiar, distribuição de renda, } \\
\text { conexão em redes, respostas políticas etc. }\end{array}$ \\
\hline 2017 & $\begin{array}{c}\text { Bellini, Nicola; } \\
\text { Grillo, } \\
\text { Francesco; } \\
\text { Lazzeri, Giulia; } \\
\text { Pasquinelli }\end{array}$ & $\begin{array}{l}\text { Revisão de } \\
\text { literatura } \\
\text { Análise } \\
\text { documental - } \\
\text { estratégias e } \\
\text { políticas regionais } \\
\text { do plano de } \\
\text { desenvolvimento } \\
\text { regional europeu }\end{array}$ & 2014-2020 & $\begin{array}{l}\text { O trabalho trata da contribuição do turismo para a } \\
\text { resiliência econômica regional e questiona as maneiras } \\
\text { como os formuladores de políticas regionais } \\
\text { reconhecem a relevância deste setor. Uma análise } \\
\text { exploratória foi realizada com foco nos documentos da } \\
\text { "Estratégia de Especialização Inteligente", elaborado na } \\
\text { Europa. Uma lista de políticas emergentes de inovação } \\
\text { envolvendo o turismo foram identificadas. Os autores } \\
\text { apontam que é importante desenvolver estudos de caso, } \\
\text { a fim de analisar o processo real que leva à estratégia e } \\
\text { implementação, detectando as prováveis lacunas entre } \\
\text { intenções estratégicas e implementação de políticas. }\end{array}$ \\
\hline 2017 & Coenen et al. & Revisão teórica & Não se aplica & $\begin{array}{l}\text { O objetivo deste artigo é investigar criticamente o que a } \\
\text { geografia econômica evolucionária traz para o campo } \\
\text { das políticas e como isso pode contribuir para uma } \\
\text { abordagem de sistemas de inovação regionais. O artigo } \\
\text { foca especialmente em como isso pode melhorar a } \\
\text { capacidade de políticas baseadas em uma estrutura } \\
\text { regional de sistema de inovação para apoiar o } \\
\text { desenvolvimento de novos caminhos (ou seja, } \\
\text { renovação de caminho e criação de novas trajetórias) } \\
\text { para garantir a resiliência regional. }\end{array}$ \\
\hline 2017 & $\begin{array}{l}\text { Grunsven, Leo } \\
\text { van; } \\
\text { Hutchinson, } \\
\text { Francis E. }\end{array}$ & $\begin{array}{l}\text { Estudo de caso } \\
\text { Uso de dados } \\
\text { secundários } \\
\text { Entrevistas } \\
\text { estruturadas com } \\
\text { empresas }\end{array}$ & $\begin{array}{l}\text { 1990-2013 } \\
\text { Indonésia - } \\
\text { Riau Islands } \\
\text { Batam. }\end{array}$ & $\begin{array}{l}\text { Os autores argumentam que não são somente fatores } \\
\text { estruturais que importam para construção da resiliência, } \\
\text { mas também questões institucionais e comportamentais. } \\
\text { Em um contexto de pouca inovação, inexistente } \\
\text { infraestrutura educacional e tecnológica e falta de } \\
\text { capital humano qualificado, a indústria de } \\
\text { eletroeletrônicos não alcançou um nível significativo de } \\
\text { robustez. }\end{array}$ \\
\hline 2017 & $\begin{array}{l}\text { Plummer, Paul; } \\
\text { McKenzie }\end{array}$ & $\begin{array}{l}\text { Estudo de caso } \\
\text { Análise de dados } \\
\text { secundários } \\
\text { Uso de análise } \\
\text { econométrica }\end{array}$ & $\begin{array}{c}\text { 1984-2014 } \\
\text { Busselton, } \\
\text { Geraldton, Broome } \\
\text { e Albany - } \\
\text { Austrália }\end{array}$ & $\begin{array}{l}\text { As evidências apresentadas neste artigo indicam que a } \\
\text { evolução dependente de centros regionais sugere que as } \\
\text { localidades estudadas são vulneráveis a choques } \\
\text { externos e perturbações. Apontam que há potencial para } \\
\text { investimentos estratégicos e oportunos para "empurrar" } \\
\text { as localidades para trajetórias de desenvolvimento de } \\
\text { longo prazo. As decisões dependem de uma } \\
\text { compreensão qualitativa dos mecanismos causais e das } \\
\text { circunstâncias locais específicas, além das evidências } \\
\text { empíricas. }\end{array}$ \\
\hline 2018 & $\begin{array}{c}\text { Bristow, } \\
\text { Gillian; Healy }\end{array}$ & $\begin{array}{l}\text { Estudo de caso } \\
\text { Análise de dados } \\
\text { secundários } \\
\text { Uso de dados } \\
\text { anuais de emprego }\end{array}$ & $\begin{array}{c}\text { 2001-2011 } \\
28 \text { países da UE } \\
\text { mais Suíça, } \\
\text { Noruega, } \\
\text { Lichtenstein e } \\
\text { Islândia }\end{array}$ & $\begin{array}{l}\text { Constatam que regiões líderes em inovação no momento } \\
\text { da crise eram significativamente mais propensas a } \\
\text { resistir à crise ou se recuperar rapidamente (dentro de } 3 \\
\text { anos). Isso fornece insights para abordagens evolutivas } \\
\text { que associam inovação e resiliência. O trabalho também } \\
\text { demonstra que, embora o nível de capacidade de } \\
\text { inovação seja uma explicação importante para entender } \\
\text { por que algumas regiões foram mais resistentes à crise } \\
\text { econômica do que outras, não é a única explicação, } \\
\text { como ilustra o caso da Polônia. Embora a inovação } \\
\text { realmente construa resiliência econômica, isso é } \\
\text { improvável de ser alcançado simplesmente através do } \\
\text { apoio às atividades de P\&D e às inovações lideradas } \\
\text { pela ciência e tecnologia. Para que as economias tenham } \\
\text { a capacidade de responder a choques, permitindo } \\
\text { resistência ou recuperação, as políticas precisam } \\
\text { também promover a capacidade de fazer, usar e } \\
\text { interagir. Economias resilientes provavelmente possuem } \\
\text { sistemas de inovação ágeis que promovem novas }\end{array}$ \\
\hline
\end{tabular}




\begin{tabular}{|c|c|c|c|c|}
\hline & & & & $\begin{array}{l}\text { combinações de atividades, onde as organizações estão } \\
\text { dispostas a aceitar riscos, e onde a adaptabilidade é } \\
\text { incorporada ao comportamento e respostas dos atores- } \\
\text { chave de uma região. }\end{array}$ \\
\hline 2018 & $\begin{array}{l}\text { Xiao, Jing; } \\
\text { Boschma, Ron; } \\
\text { Andersson }\end{array}$ & $\begin{array}{l}\text { Estudo de caso } \\
\text { Uso de dados } \\
\text { secundários (dados } \\
\text { de emprego, } \\
\text { diversificação } \\
\text { industrial, } \\
\text { Quociente } \\
\text { Locacional (QL)) }\end{array}$ & $\begin{array}{l}2004-2012 \\
173 \text { regiões } \\
\text { europeias em } 12 \\
\text { países }\end{array}$ & $\begin{array}{l}\text { Mostram que há diferenças significativas entre as } \\
\text { regiões da Europa em termos de diversificação } \\
\text { industrial. Também fornecem evidências de que a } \\
\text { probabilidade de uma nova especialização industrial se } \\
\text { desenvolver em uma região está positivamente } \\
\text { associada à relação da nova indústria com as indústrias } \\
\text { atuais da região. A probabilidade de novas } \\
\text { especializações industriais se desenvolverem também } \\
\text { depende da capacidade de inovação de uma região. } \\
\text { Constatam que a capacidade de inovação é um fator } \\
\text { crítico para a resiliência econômica e a capacidade de } \\
\text { diversificação. }\end{array}$ \\
\hline 2018 & $\begin{array}{l}\text { Antonietti, } \\
\text { Roberto; } \\
\text { Boschma }\end{array}$ & $\begin{array}{l}\text { Estudo de caso } \\
\text { Análise de dados } \\
\text { secundários } \\
\text { (número de plantas } \\
\text { industriais e } \\
\text { funcionários, por } \\
\text { setor e região) }\end{array}$ & $\begin{array}{l}\text { 2004- } 2010 \\
\text { Províncias italianas } \\
\text { Uso dos dados } \\
\text { sobre } 756 \\
\text { indústrias e } 103 \\
\text { regiões na Itália }\end{array}$ & $\begin{array}{l}\text { Os resultados mostram que a introdução de profissionais } \\
\text { com novas habilidades em uma região contribui } \\
\text { positivamente para a entrada de novas indústrias, } \\
\text { especialmente quando não estão relacionadas às } \\
\text { especializações existentes na região. A diversificação } \\
\text { nas regiões (especialmente mais diversificadas e não- } \\
\text { relacionadas) tende a depender deste efeito (vinda de } \\
\text { novas habilidades), e não da conexão do capital social já } \\
\text { existente. Também constatam que essa "importação" de } \\
\text { capital social perde seu impacto na diversificação } \\
\text { regional durante a crise e, embora isso tenha um efeito } \\
\text { negativo sobre a saída em tempos de prosperidade, não } \\
\text { se demonstra tal efeito durante o período de crise. Em } \\
\text { suma, os achados sugerem que a vinda de profissionais } \\
\text { com novas habilidades, a "importação" de capital social, } \\
\text { perde seu papel de apoio em tempos de crise. }\end{array}$ \\
\hline 2018 & $\begin{array}{l}\text { Xiao, Jing; } \\
\text { Boschma, Ron; } \\
\text { Andersson }\end{array}$ & $\begin{array}{l}\text { Estudo de caso } \\
\text { Análise de dados } \\
\text { secundários } \\
\text { (emprego e entrada } \\
\text { da indústria em } \\
\text { regiões europeias; } \\
\text { Quociente } \\
\text { Locacional }(\mathrm{QL}) \text { ). }\end{array}$ & $\begin{array}{c}2004-2012 \\
173 \text { regiões } \\
\text { europeias em } 12 \\
\text { países }\end{array}$ & $\begin{array}{l}\text { As análises mostram que as regiões europeias diferem } \\
\text { amplamente em sua capacidade de criar caminhos da } \\
\text { indústria após a crise de } 2008 \text {. Como esperado, as } \\
\text { variedades relacionada e não-relacionada são fatores } \\
\text { cruciais que aumentam a probabilidade de uma região } \\
\text { ser resiliente. Isso se aplica especialmente à variedade } \\
\text { relacionada que mostra um efeito positivo mais forte } \\
\text { sobre a resiliência regional. }\end{array}$ \\
\hline 2019 & $\begin{array}{c}\text { Hu, Xiaohui; } \\
\text { Yang }\end{array}$ & $\begin{array}{l}\text { Estudo de caso } \\
60 \text { Entrevistas em } \\
\text { profundidade } \\
\text { Dados secundários } \\
\text { e análise } \\
\text { documental }\end{array}$ & $\begin{array}{c}2013-2016 \\
\text { Zaozhuang na } \\
\text { província de } \\
\text { Shandong e Fuxin } \\
\text { na província de } \\
\text { Liaoning. } \\
\text { China }\end{array}$ & $\begin{array}{l}\text { O estudo aponta que uma perspectiva de mudança } \\
\text { institucional permite examinar os mecanismos de } \\
\text { desenvolvimento de trajetórias que refletem de forma } \\
\text { abrangente capacidades, escopos e agendas de } \\
\text { resiliência em regiões e cidades. As formas pelas quais } \\
\text { as instituições e os caminhos industriais coevoluem não } \\
\text { são apenas condicionadas por ativos e histórias } \\
\text { específicas do local, mas também dependem de como os } \\
\text { agentes entendem e impactam nas instituições e } \\
\text { contextos de tempo-espaço. }\end{array}$ \\
\hline 2019 & Prokkola & $\begin{array}{l}\text { Estudo de caso } \\
\text { Entrevistas com } \\
\text { stakehoders } \\
\text { Análise dados } \\
\text { secundários }\end{array}$ & $\begin{array}{c}\text { 2016-2017 } \\
\text { Cidades } \\
\text { finlandesas de } \\
\text { Lappeenranta e } \\
\text { Tornio }\end{array}$ & $\begin{array}{l}\text { O estudo aponta que o ambiente geopolítico e a abertura } \\
\text { da fronteira determinam em parte as trajetórias de } \\
\text { desenvolvimento regional e as formas de lidar com as } \\
\text { mudanças transfronteiriças relacionadas à mobilidade. }\end{array}$ \\
\hline 2019 & $\begin{array}{l}\text { Machado, } \\
\text { Claralucia } \\
\text { Prates et al. }\end{array}$ & $\begin{array}{c}\text { Estudo de caso } \\
\text { Pesquisa-ação } \\
\text { Modelo Dinâmico } \\
\text { de sistemas } \\
\text { (contando com }\end{array}$ & Não se aplica & $\begin{array}{l}\text { O estudo avaliou a dinâmica da indústria calçadista em } \\
\text { uma cidade (não especificada) do sul do Brasil, buscando } \\
\text { desenvolver um modelo dinâmico que pudesse explicar } \\
\text { os processos da indústria, projetar cenários que simulem } \\
\text { a capacidade de melhoria nesses processos e aumentar a } \\
\text { resiliência regional. A pesquisa-ação foi utilizada como } \\
\text { método de pesquisa, devido ao envolvimento } \\
\text { participativo que ocorre entre os pesquisadores e os } \\
\text { participantes para compreender a situação e construir o } \\
\text { modelo dinâmico sistêmico do impacto da atividade } \\
\text { calçadista deste município sobre sua resiliência. O }\end{array}$ \\
\hline
\end{tabular}




\begin{tabular}{|c|c|c|c|c|}
\hline & & $\begin{array}{l}\text { análise de } \\
\text { informações } \\
\text { primárias e } \\
\text { secundárias) }\end{array}$ & & $\begin{array}{l}\text { modelo dinâmico de sistemas se baseou em dados de } \\
\text { entrada, a opinião de especialistas do setor, equações de } \\
\text { desempenho e funções gráficas. Este proporcionou } \\
\text { melhor entendimento dos fatores e elementos que } \\
\text { interagem e influenciam na resiliência regional e nas } \\
\text { melhorias nos processos produtivos na indústria de } \\
\text { calçados, auferindo que o investimento empresarial } \\
\text { simultâneo em fatores como marketing, tratamento de } \\
\text { resíduos e treinamento da mão de obra contribuem para } \\
\text { aumentar a resiliência na região onde essas empresas } \\
\text { atuam. Assim, neste caso, concluem que a resiliência } \\
\text { poderia ser alcançada mais facilmente se os cenários de } \\
\text { qualificação de mão de obra, marketing de valor } \\
\text { agregado e tratamento de resíduos sólidos fossem } \\
\text { aplicados simultaneamente. }\end{array}$ \\
\hline 2020 & $\begin{array}{l}\text { Plechero, } \\
\text { Monica; } \\
\text { Kulkarni, } \\
\text { Mandar; } \\
\text { Chaminade, } \\
\text { Cristina; } \\
\text { Parthasarathy }\end{array}$ & $\begin{array}{l}\text { Estudo de caso } \\
\text { Realização de } \\
\text { entrevistas } \\
\text { semiestruturadas }\end{array}$ & $\begin{array}{c}\text { 2016-2017 } \\
\text { Pequim (China) } \\
\text { Bangalore (Índia) }\end{array}$ & $\begin{array}{l}\text { O artigo investigou como as trajetórias dos Sistemas } \\
\text { Regionais de Inovação (SRI), conceituados como } \\
\text { conjunto de instituições distintas que contribuem para o } \\
\text { desenvolvimento da capacidade de inovação de uma } \\
\text { região ou município, de Bangalore e Pequim } \\
\text { influenciam os objetivos e a configuração geográfica } \\
\text { das redes de inovação na nova indústria de mídia. A } \\
\text { coevolução de diferentes elementos da trajetória do SRI } \\
\text { aponta para o desdobramento de uma trajetória } \\
\text { politicamente e institucionalmente impulsionada em } \\
\text { Pequim, e uma trajetória cognitivamente conduzida em } \\
\text { Bangalore. Essas trajetórias levam a barreiras e } \\
\text { oportunidades específicas para o desenvolvimento de } \\
\text { redes de inovação em novas indústrias. }\end{array}$ \\
\hline
\end{tabular}

Fonte: os autores (2021)

Para explicitar de outra forma o foco que os trabalhos analisados possuem, foram avaliadas as palavras-chave destes trabalhos por meio da ferramenta de 'nuvem de palavras', conforme apresentado na Figura 1. Nesta Figura, o tamanho da palavra representa sua incidência (frequência) no grupo de palavraschave dos periódicos avaliados, ou seja, quanto maior o tamanho da palavra na "nuvem", maior a sua incidência nos trabalhos analisados. Excluindo-se os termos "resiliência regional" e "resiliência", que obviamente obteriam muito destaque, evidenciaram-se com mais destaque os termos "econômica", "evolucionária", "social", "política", "regional e "sistemas".

Figura 1 - Nuvem de palavras identificada



Fonte: os autores (2021)

A síntese dos estudos expostos auxilia na compreensão de que diferentes abordagens e metodologias são utilizadas para se avaliar a resiliência regional. Na maioria dos trabalhos analisados, a combinação de fontes de dados secundários e primários auxiliaram na análise da resiliência. A próxima 
subseção discorre a respeito do conceito de resiliência regional, sua perspectiva evolucionária, e apresenta mais informações dos casos empíricos realizados.

\subsection{Conceito de Resiliência Regional}

Existe uma diversidade de discursos e interpretações em relação ao conceito de resiliência regional. Como diz Martin (2012), há uma falta de consenso sobre o significado do termo, não consistindo em um conceito unitário com uma definição precisa e universalmente aceita. A palavra resiliência vem do latim resilire e denota a ideia de recuperação, restabelecimento, a capacidade elástica de uma entidade ou sistema para recuperar sua forma e posição após uma alteração de qualquer tipo. Posteriormente, na década de 1950, foi utilizado por Holling, pesquisador importante, em pesquisas interdisciplinares sobre relações sustentáveis entre a população e recursos naturais de um sistema ecológico (Sánchez-Zamora; GallardoCobos; Ceña, 2016). Conforme citam Exterckoter, Pujol e Silva (2016), o processo de migração do conceito para as ciências sociais e econômicas é complexo e contraria a premissa de equilíbrio, muito comum às ciências biológicas, já que a ideia de resiliência reconhece a hipótese de que deve haver capacidade adaptativa nos territórios, principalmente nas regiões em contextos desfavoráveis.

Falando sobre seu conceito, resiliência pode ser definida como a capacidade permanente de um território de conceber e implantar novos recursos e capacidades, que lhe permitam adaptar-se favoravelmente à dinâmica de transformação, impulsionada pelas mudanças do ambiente. Nesse caso, pode-se afirmar que o território desenvolve uma resiliência dinâmica caracterizada pela capacidade de adaptação e de aprendizado de longo prazo, diante de mudanças externas e/ou internas (Simmie; Martin, 2010; Pendall; Foster; Cowell, 2010; Pike; Dawley; Tomaney, 2010; Hassink, 2010). Em suma, regiões resilientes seriam aquelas que se adaptam de forma mais rápida à mudança, que são menos vulneráveis a choques externos e turbulências e, também, que possam responder mais rapidamente para evitar dificuldades socioeconômicas.

Martin (2012), Martin e Sunley (2015) e Bellini et al. (2017) consideram três tipos de resiliência: a) "resiliência de engenharia", que significa o "retorno" de um sistema após um choque na sua estado ou caminho preexistente; b) "resiliência ecológica", significando a capacidade do sistema de absorver o choque sem alterar sua estrutura, identidade e função, mas em um estado ou caminho alternativo e; c) "resiliência adaptativa", envolvendo alguma transformação estrutural e operacional em várias escalas e prazos, para que o sistema "avance" para um caminho renovado e reajustado, e que deriva da teoria de sistemas adaptativos complexos.

Nesse sentido, Martin (2012) frisa que a resiliência regional nesse contexto poderia ser vista como tendo a capacidade de uma economia regional de reconfigurar, ou seja, adaptar sua estrutura (empresas, indústrias, tecnologias e instituições), a fim de manter um caminho de crescimento na produção, emprego e riqueza ao longo do tempo. A resiliência pode potencialmente permitir uma perspectiva de longo prazo sobre o desenvolvimento econômico regional, diferentemente do foco apenas no crescimento, pois aponta para a capacidade de uma economia regional manter o desempenho por um período mais longo (Evenhuis, 2017). Essa adaptabilidade depende da taxa de empreendedorismo e da formação de novas empresas na região, da capacidade de inovação das empresas existentes e de sua capacidade e vontade de mudar para novos setores e linhas de produtos, do acesso ao financiamento para investimentos, da diversidade de estrutura econômica da região, sobre a disponibilidade de mão de obra com as habilidades certas e fatores semelhantes (MARTIN, 2012).

Pendall, Foster e Cowell (2010) apresentam um modelo de ciclos adaptativos em quatro fases para resiliência dos sistemas. Cada fase do ciclo adaptativo se associa a um nível de resiliência, medido como a vulnerabilidade do sistema em surpreender, estressar e chocar. O modelo de ciclo adaptativo apresenta os maiores níveis de resiliência quando um sistema exibe seu maior fluxo e flexibilidade. Os autores também reforçam as diferentes maneiras em que se pode estudar resiliência. Como exemplo, citam um pesquisador que estuda o ajuste de uma região à desindustrialização, onde, nesse caso, media a resiliência como, por exemplo, uma redução gradual na taxa de desemprego na economia regional. Em vez de um suposto equilíbrio, o ponto de referência se torna o passado recente em constante mudança, como "ano passado" ou "trimestre anterior". Se a região melhorou em algum desses resultados desde o período anterior ou, pelo menos, não piorou, o pesquisador concluiria que é mais resiliente do que em uma região onde os resultados se deterioraram (Pendall; Foster; Cowel, 2010). Porém, também propõem que a classificação de uma região como resiliente seja mais precisa, afirmando que só se poderá considerá-la como tal caso, diante de um desafio, mantiver ou melhorar seu desempenho nos resultados, independentemente do esforço, processo ou ponto de partida.

\subsection{Perspectiva Evolucionária da resiliência regional}

A introdução do pensamento evolucionário no que tange à resiliência regional se fundamenta na história e 
geografia dos lugares, reconhecendo a importância das especificidades locais para explicar como a organização espacial da produção, distribuição e consumo são transformados ao longo do tempo. Recentemente, vários conceitos relacionados com a geografia econômica evolucionária, como o path dependence, lock-in, coevolução ou fragmentação dos ciclos de vida têm sido utilizados a fim de teorizar sobre as questões relacionadas à adaptação regional (BRISTOW; HEALY, 2018; BOSCHMA, 2015; MARTIN; SUNLEY, 2015; SIMMIE; MARTIN, 2010; MARTIN, 2012).

Martin (2012) e Boschma (2015) complementam o conceito, apresentando a resiliência regional evolucionária, que aborda a capacidade de longo prazo das regiões de desenvolverem novas trajetórias de crescimento, numa perspectiva de evolução do sistema, não somente focando em absorção pontual de choques específicos, mas também valendo-se das estruturas e potenciais, seja de instituições, capital social, habilidades, entre outras características, já existentes. Autores que versam sobre o conceito de resiliência regional nessa perspectiva propõem uma conceitualização na qual a história é fundamental para entender como as regiões desenvolvem novas trajetórias de crescimento, já que estruturas industriais, de rede e institucionais existentes nas regiões oferecem oportunidades, mas também estabelecem limites ao processo de diversificação e desenvolvimento de novas perspectivas (Boschma, 2015). O path dependence é um processo em que o desempenho e os respectivos resultados de um dado sistema evoluem como consequência da sua própria história. Já o conceito de lock-in está associado às dificuldades de reestruturação necessárias às economias regionais para sua adaptação às mudanças. Esses dois conceitos estão intimamente relacionados, pois, dependendo da estratégia (ou caminho) escolhido, pode-se dificultar os processos de reestruturação necessários (MARTIN, 2012; MARTIN; SUNLEY, 2015; SENSIER; BRISTOW; HEALY, 2016).

Os trabalhos de Boschma (2015) e Martin e Sunley (2015) tornam-se importantes para compreender a lógica da perspectiva evolucionária de resiliência regional. Os autores objetivam, através disso, desenvolver um conceito mais abrangente de resiliência regional que capture dimensões industriais, de rede e institucionais de regiões que foram ignoradas na literatura de resiliência ou tratadas separadamente. Assim, afastam-se do significado da resiliência como sendo a capacidade das regiões se recuperarem de um choque, e redefinem a resiliência regional em termos do impacto de um choque na capacidade de uma região de desenvolver novas trajetórias de crescimento. Nessa perspectiva evolucionária, a resiliência consiste na capacidade de uma região sustentar o desenvolvimento no longo prazo, sendo considerada tão importante quanto à capacidade de uma região responder positivamente a choques de curto prazo.

Assim, a resiliência depende da capacidade das regiões lidarem com mudanças estruturais, criando novas trajetórias de crescimento para compensar processos inevitáveis de estagnação e declínio em sua economia regional, pois se entende que a região não pode confiar unicamente em seu legado de sucessos passados para ter garantias de conseguir repetir tais feitos no futuro (Saviotti 1996 apud Boschma 2015). Nessas abordagens, deve-se pensar não apenas em empresas e indústrias, mas também nas políticas de desenvolvimento local e regional e, num sentido mais amplo, de que modo as mudanças ambientais, condições hierárquicas, redes de relacionamento e inovação, afetam o dinamismo e a adaptabilidade das economias regionais e que medidas devem ser tomadas para auxiliar na adaptação econômica regional. Esses conceitos podem, potencialmente, explicar porque algumas economias regionais perdem dinamismo e outras não (MARTIN; SUNLEY, 2015; PLECHERO et al., 2020).

Boschma (2015) argumenta que a adaptabilidade a longo prazo das regiões é condicionada por seu legado industrial, de rede e institucional, que oferece oportunidades, mas também estabelece limites para que os atores locais sejam resilientes. O autor também propôs uma estrutura evolutiva que explora quais determinantes da resiliência regional podem superar o trade-off entre adaptação e adaptabilidade, de modo a aprimorar a resiliência das regiões em termos de capacidade de desenvolver novas trajetórias de crescimento. Essa estrutura concentra a atenção na estrutura da base de conhecimento industrial regional (XIAO; BOSCHMA; ANDERSSON, 2018a).

A adaptação pode ser entendida como a capacidade de responder a um choque econômico com um movimento de retorno, pelo menos em curto prazo, a um modelo pré-concebido de desenvolvimento regional ou setorial que pode ter sido bem-sucedido antes do choque. Por outro lado, a adaptabilidade pode explicar um tipo diferente de resiliência e que pode ser necessário para lidar com eventos imprevistos no futuro. A resiliência através da adaptabilidade surge através de oportunidades ou decisões para deixar um caminho que pode ter se mostrado bem-sucedido no passado em favor de uma trajetória ou nicho novo, relacionado ou alternativo (Dawley; Pike; Tomaney, 2010; Pike, Dawley, Tomaney, 2010). Em suma, a adaptação diz respeito a mudanças em caminhos pré-concebidos, enquanto a adaptabilidade é sobre o desenvolvimento de novos caminhos, ou seja, partidas dos caminhos existentes (Boschma, 2015). Pike, Dawley e Tomaney (2010) afirmam que as abordagens evolucionárias tratam sobre como as diferentes características de adaptação e adaptabilidade podem ajudar a explicar a maneira com que os diferentes componentes de uma economia regional (setores, mercados de trabalho, interesses políticos etc.) se 
integram para fornecer formas complexas, frequentemente fragmentadas e variadas de resiliência, explicando a resiliência geograficamente desigual dos lugares.

Baseando-se em conceitos de inovação e de crescimento regional, Boschma (2015) propôs duas variáveis evolutivas principais, ou seja, variedade relacionada e não relacionada, que podem afetar a resiliência regional, promovendo sua importância para a "construção de vantagem regional" entre os formuladores de políticas da UE (Pike; Dawley; Tomaney, 2010; Xiao; Boschma; Andersson, 2018b). Boschma (2015) diz que a variedade não relacionada, ou seja, um alto nível de diversificação sem vínculos entre as indústrias da região diminui a vulnerabilidade a choques externos, pois há menos risco de o sofrimento da economia regional devido a efeitos contagiosos por meio de vínculos intersetoriais na região. Já a variedade relacionada, aumenta o potencial de recombinação de uma região, e fornece recursos locais (relacionados) nos quais novas trajetórias de crescimento podem ser construídas e desenvolvidas. Consequentemente, a variedade relacionada relaxa o trade-off entre adaptabilidade e adaptação que pode ocorrer em regiões diversificadas. É mensurada por vínculos tecnológicos, habilidades ou produção existente. Pode aumentar a vulnerabilidade a choques externos, mas como citado, consegue suportar a adaptabilidade em uma região, pois fatores liberados de indústrias afetadas negativamente podem ser transferidos para indústrias relacionadas com características de demanda diferentes (BOSCHMA, 2015; WINK, 2014).

Percebe-se que regiões com um conjunto diversificado de indústrias acomodam melhor os choques, e isso ocorre porque se espera que trabalhadores encontrem empregos com mais facilidade em indústrias locais relacionadas à habilidade pré-existentes e que foram afetadas negativamente por um choque externo Porém, além desse efeito de combinação de mão de obra regional de variedade relacionada, as regiões diversificadas também podem ter mais potencial para fazer novas recombinações em indústrias locais. De fato, estudos recentes, como o de Neffke et al. (2011) ou de Xiao, Boschma e Andersson (2018a), ressaltam que as regiões se diversificam em atividades relacionadas às atividades locais existentes, nas quais as capacidades locais são recombinadas em novas opções. Portanto, a variedade relacionada pode não apenas aumentar a capacidade das regiões de absorver choques, mas também aumentar sua capacidade de desenvolver novos caminhos de crescimento. Importante ressaltar essa conexão com estruturas pré-existentes, pois há, segundo Boschma (2015), uma tendência na literatura (enganosa, na visão do autor) de associar a adaptabilidade regional às novas trajetórias de crescimento que são distantes de seu passado, como se a dependência em relação a este causasse apenas problemas. $\mathrm{O}$ autor argumenta que o passado tem uma forte marca na resiliência regional, não apenas em termos de restrições, mas também em termos de oportunidades, pois define o escopo para a reorientação de habilidades, recursos, tecnologias e instituições nas regiões.

Ao contrário das regiões diversificadas, regiões especializadas combinam alta adaptação com baixa adaptabilidade para desenvolver novas trajetórias de crescimento, devido a um menor potencial de recombinação e um possível estado de bloqueio negativo. Regiões especializadas podem superar esse trade-off, através de estratégias de como ativar recursos locais não comprometidos ou habilidades redundantes, utilizando sua base de conhecimento especializado para diversificar-se em novas atividades relacionadas e conectar-se a indústrias e a tecnologias em outras regiões, das quais podem extrair recursos (relacionados) e recombinar aqueles com sua própria base de conhecimento local (BOSCHMA, 2015).

O conhecimento e a inovação ganham destaque nessa perspectiva. Coenen et al. (2016) reforçam que a maior atenção deve ser direcionada às oportunidades de processos amplos e contínuos de geração de conhecimento, formação de recursos humanos e desenvolvimento de capacidades na indústria e em interação com organizações públicas de pesquisa e educação. Essa abordagem defende a intervenção de políticas para promover a diversificação econômica e a resiliência das regiões por meio de políticas personalizadas baseadas na relação entre as indústrias e na combinação de bases de conhecimento em um contexto de cooperação público-privada. De fato, Crespo, Suire e Vicente (2014) comentam que resiliência regional e ciclos de vida de cluster são conceitos que surgiram recentemente na literatura e buscam entender o processo evolutivo através do qual um ecossistema regional de organizações e instituições consegue manter seu caminho de crescimento.

Assim, o ecosistema de inovação e a interação entre os atores deste ganha importância, onde o conhecimento pode ser compartilhado. Dessa maneira, o conceito de Hassink (2010) de região de aprendizagem parece condizente com o exposto em relação à inovação, consistindo em uma estratégia regional de inovação, na qual um amplo conjunto de atores regionais relacionados à inovação, tais quais políticos, policy makers, câmaras de comércio, sindicatos, instituições de ensino superior, instituições públicas de pesquisa e empresas, estão fortemente conectados com a promoção o desenvolvimento de novas capacidades. A natureza e a fonte da adaptabilidade nas regiões parecem essenciais para a resiliência, com os geógrafos econômicos evolucionários cada vez mais afirmando que é a capacidade de inovação das regiões ou sua capacidade de se reinventar continuamente que é central para essa adaptabilidade. As regiões estão sujeitas a um processo interminável de destruição criativa, tal qual presente na visão schumpeteriana, onde, em longo prazo, as regiões dependem de sua capacidade de diversificar com sucesso 
e desenvolver novos caminhos de crescimento que são considerados essenciais para compensar processos inevitáveis de declínio (Xiao; Boschma; Andersson, 2018b). É provável que economias resilientes tenham sistemas de inovação ágeis que promovam novas combinações de atividades, nas quais as organizações estão dispostas a aceitar riscos e onde a adaptabilidade é incorporada ao comportamento e às respostas dos principais atores da região. Quanto mais opções estiverem disponíveis quando um choque ocorrer, maior será a probabilidade de uma dessas opções fornecer uma rota positiva e eficaz durante a crise e, de fato, um novo caminho além dela. A inovação é, portanto, uma mentalidade e uma capacidade, tanto quanto um resultado do desempenho da empresa. As regiões inovadoras podem estar mais bem equipadas para responder porque exibem uma atitude proativa com a dinâmica e a necessidade de mudança (BRISTOW; HEALY, 2018).

\subsection{Métodos de pesquisa empregados nos estudos de resiliência regional e formas de mensuração}

De acordo com Martin e Sunley (2015) e Courvisanos, Ameeta e Mardaneh (2015), falta consenso em relação à mensuração da resiliência, uma vez que autores diferentes empregam definições e descrições diferentes para resiliência regional, sendo que ainda não existe uma metodologia geralmente aceita de como o conceito deve ser operacionalizado e medido empiricamente. Dessa forma, preconizam que o estudo da resiliência requer a especificação de um estado, regime ou caminho significativo de "referência" em relação ao qual o impacto de um choque pode ser medido e a extensão e natureza da recuperação desse choque podem ser julgadas. Consequentemente, qualquer abordagem de medição enfrenta o desafio de capturar essa complexidade conceitual de uma maneira que permanece significativa e útil (SENSIER; BRISTOW; HEALY, 2016).

Duschl (2016) cita que as tentativas empíricas de medir a resiliência regional geralmente analisam mudanças em algum indicador regional, por exemplo, taxa de desemprego, nível de emprego ou renda, para avaliar o impacto de um choque externo no caminho de crescimento de uma economia regional.

Os trabalhos avaliados possuem diferentes abordagens em relação à forma de se medir resiliência. Eraydin (2015), no seu estudo sobre regiões turcas, utiliza o PIB para auferir o impacto dos choques recessivos, já que na Turquia os dados sobre emprego são menos confiáveis devido à alta proporção de mão de obra não registrada. Sensier, Bristow e Healy (2016) adotam metodologia similar em seu trabalho, utilizando duas séries de dados: primeiro, o nível de emprego em uma região e, segundo, o nível do Produto Interno Bruto (PIB). Pragmaticamente, ambos estão constantemente disponíveis em uma base comparativa em todo o território da UE. Concordando, Wink (2014) afirma que, tradicionalmente, os conceitos regionais de desempenho econômico focam particularmente nos indicadores de desempenho econômico convencional nas análises econômicas, como Produto Interno Bruto (PIB), Valor Agregado Bruto (VAB) e taxa de emprego ou desemprego. Mas o autor também traz o exemplo do Instituto Alemão Pestel, que procurou indicadores de resiliência em nível regional através de outros indicadores, como previdência social, moradia, transporte, energia, economia e uso da terra.

Em seu estudo sobre a economia australiana, Plummer e McKenzie (2017) empregam modelos e métodos da econometria dinâmica contemporânea para aprimorar a compreensão do cenário econômico em evolução e corrigir o desequilíbrio entre a teoria e a prática do pensamento da resiliência. Frisam que embora o uso de modelos econométricos para explorar a resiliência das economias regionais esteja em sua infância, usando modelos e métodos econométricos, conseguem responder à pergunta da pesquisa: como as regiões reagem ao "choque"? Também, o estudo de Navarro-Espiragarres, Martín-Segura, HernándezTorres (2012) testa a hipótese sobre a influência do setor de serviços na resiliência econômica regional espanhola, usando uma série temporal de valor agregado bruto e emprego para as 17 regiões espanholas durante o período 1986-2009, concluindo que, tanto na crise econômica de 1992 como na de 2008, as regiões intensivas em atividades relacionadas à serviços demonstraram maior resiliência, possuindo maior resistência à perda de $\mathrm{VAB}$ e de empregos.

Procurando auferir a resiliência e resposta bem-sucedida de uma região a um choque, refletindose na sua capacidade de reestruturar e reorientar seus recursos regionais (capital, trabalho, conhecimento, instituições, redes etc.) e mover sua economia regional para novas especializações do setor, Xiao, Boschma e Andersson (2018a) comparam os níveis de entrada de novas indústrias especializadas nas regiões antes e depois da crise de 2008. Para tanto, dividiram os dados em dois períodos de quatro anos: um período de pré-recessão (2004-2008) e um período durante e após a recessão (2008-2012). Courvisanos, Jain e Mardaneh (2015) dizem que uma região resiliente adaptável demonstrará mudanças na natureza da indústria ao longo do tempo, sem redução significativa no emprego ou na renda, apesar de choques ou perturbações, e, dessa forma, no artigo em questão, a medida da adaptabilidade em longo prazo é avaliada pelas mudanças na estrutura da indústria das regiões. Pendall, Foster e Cowell (2010) citam que, por exemplo, uma medida da resiliência de uma região diante da desindustrialização em longo prazo pode ser a reindustrialização (talvez com empregos com salários mais altos). 
Ressalta-se a afirmação de Martin e Sunley (2015), que preconizam que existem várias maneiras possíveis de medir o grau e a "forma" da resiliência de uma região a um choque econômico, e para tanto podem ser encontradas na literatura diferentes abordagens metodológicas para essa questão, variando de estudos de caso descritivos e interpretativos a modelos estatísticos e econométricos sofisticados, usando funções de impulso e similares, para medir velocidades de recuperação regional e outros recursos do tipo, cada um com seus usos, méritos e limitações, onde a combinação de diferentes métodos pode ser uma estratégia adequada.

\subsection{Estudos e evidências empíricas sobre resiliência regional}

Conforme citado anteriormente, casos empíricos sobre o conceito de resiliência regional aplicado à realidade de países emergentes não são tão comuns na literatura. O objetivo dessa seção é resgatar os casos empíricos e análises que os artigos selecionados trazem, iniciando com casos brasileiros e ir, de forma gradativa, apresentando casos de países emergentes e, posteriormente, outras nações ou casos da União Europeia. Os textos aplicaram o conceito de resiliência regional, mas empregando-o de formas diferentes (alguns focaram na comparação de políticas públicas, na mudança de contexto político, alterações nas características institucionais, etc). Alguns tratam de casos de nações (ou de diferentes regiões dentro de um país) e outros artigos tratam de regiões específicas. Tais diferenças no emprego do conceito auxiliam a compreender suas nuances.

No Brasil, Pitteri e Bresciani (2014) analisam o caso do Polo Industrial de Cubatão (SP), ressaltando como essa região conseguiu reverter uma situação iminente de desindustrialização por meio de esforços conjuntos. Com relação aos aspectos econômicos e aos objetivos propostos no Plano de Ação para a Recuperação Ambiental, é possível afirmar que ocorreu uma transformação regional com desempenho superior à situação anterior ao choque em relação ao crescimento econômico e redução de poluentes do ar. Machado et al. (2019), conduzindo estudo sobre indústria calçadista na região sul do Brasil, tiveram como objetivo analisar o processo dessa indústria e seu impacto sobre a resiliência da cidade. O sistema estudado compreendeu conjunturas das últimas décadas que transformaram o foco produtivo da "commodity de calçados" por calçados de alto valor agregado, com foco em diferenciação. Verificou-se que, utilizando as ações estratégicas produzidas pelo novo modelo de negócios, a influência da variação cambial não era mais um fator relevante e que a resiliência poderia ser mais facilmente alcançada se os cenários de qualificação do trabalho, marketing de valor agregado e tratamento de resíduos sólidos fossem aplicados simultaneamente. Foi possível, por meio do modelo dinâmico proposto, avaliar a interação entre os elementos e fatores que impactam a resiliência de uma região, verificando se os investimentos corporativos nesses determinantes da resiliência, efetuados de forma equilibrada ao longo do tempo, contribuem positivamente para aumentar resiliência regional.

Analisando o papel do lugar e do capital social no período de emergência após o terremoto de 27 de fevereiro de 2010 no Chile, González-Muzzio (2013) indica que ambos os fatores modificaram fortemente a resiliência inerente à cidade e sua comunidade. Os habitantes das áreas afetadas foram forçados a se adaptar rapidamente à nova situação, aproveitando os recursos disponíveis na área. $\mathrm{O}$ surgimento de novos grupos e comportamentos emergentes, bem como as características do local, contribuíram positivamente para melhorar a resiliência adaptativa da comunidade. Esses fatores devem ser considerados no planejamento e/ou reconstrução de cidades com níveis mais altos de resiliência.

Ao estudar a incidência da crise financeira global de 2008-2009 entre diferentes nações, Didier, Hevia e Schmukler (2012) ressaltam uma quebra estrutural na maneira como as economias emergentes reagiram ao choque global. Ao contrário da percepção popular, as economias emergentes sofreram colapsos de crescimento em relação aos níveis anteriores à crise, similares aos experimentados pelas economias desenvolvidas. Um sinal de resiliência para as economias emergentes é que elas iniciaram sua recuperação mais cedo do que as economias avançadas, retornando às taxas de crescimento mais altas antes da crise e, consequentemente, convergindo mais rapidamente para a tendência de produção de longo prazo. A maioria das economias retornou às taxas de crescimento pré-crise. Embora as economias emergentes não tenham sido capazes de evitar o colapso originado nos EUA e depois transmitidas pelos países, elas foram mais resistentes durante a crise global do que nas crises passadas. Eles retomaram suas taxas de crescimento mais altas anteriormente e convergiram mais rapidamente para sua tendência de crescimento pré-crise. Além disso, as economias emergentes não caíram mais do que as economias desenvolvidas durante a crise global e foram capazes de conduzir políticas anticíclicas, tornando-se mais semelhantes às economias desenvolvidas. Harrison e Sepúlveda (2011) também ressaltam estas questões em seu trabalho, onde apresentam evidências empíricas do melhor desempenho de crescimento dos países em desenvolvimento antes e depois da crise econômica e financeira de 2008-2009, ressaltando que os países em desenvolvimento se tornaram mais sofisticados em gestão fiscal.

Falando sobre o caso da Turquia, Eraydin (2015), através de uma discussão sobre os impactos da recessão nas regiões turcas, apresenta uma exploração empírica do conceito de resiliência regional. As 
conclusões apontam várias áreas políticas específicas que devem ser priorizadas. Primeiro, eles mostram a importância de políticas que aumentem o capital humano e a inovação na construção de capacidade, o que leva a uma maior resiliência e capacidade de autotransformação. Os resultados também enfatizam a importância de recursos financeiros e acesso a créditos, além da distribuição de oportunidades de emprego e renda existentes. Também, as descobertas revelam a necessidade de uma revisão das instituições, políticas e medidas existentes.

Focando no setor de eletroeletrônicos na Ilha de Batam (província de Riau Islands, Indonésia), Grunsven e Hutchinson (2017) examinam a evolução do setor, resiliência da região, e notam que ele vem decrescendo. Como a promoção da diversificação econômica por meio do investimento em novos setores é mais fácil e lucrativa do que a atualização e o aprofundamento das capacidades da empresa nos setores existentes, os agentes privilegiam a primeira à custa da segunda. A pesquisa com empresas que operam em Batam também revelou que elas ocupam os degraus mais baixos e menos valorizados dentro de suas próprias hierarquias corporativas. Os recursos mais avançados são em grande parte irrelevantes para eles, e novas tecnologias e recursos são adquiridos em outros lugares. Embora algumas empresas restantes comprometidas tenham processos de produção automatizados, isso ocorreu devido à falta de mão de obra qualificada, e não a um desejo intrínseco de se atualizar por si só. No contexto de pouca inovação, infraestrutura educacional e tecnológica inexistente e falta de capital humano qualificado, a indústria de eletroeletrônicos não alcançou um nível significativo de robustez.

Hu e Yang (2019) propõem um estudo comparativo sobre o desenvolvimento de trajetórias divergentes que envolvem mecanismos institucionais de mudança distintos em duas cidades mineiras chinesas que enfrentam o esgotamento de recursos desde 2000: Zaozhuang, na província de Shandong e Fuxin, na província de Liaoning. Como resultado, mostra que em cidades como Zaozhuang, os agentes de mudança são capazes de moldar instituições mais amplas, em parte por causa da agência empreendedora e em parte por causa da falta de intervenções e controles de políticas. Assim, essas cidades podem facilitar a criação e a renovação de trajetórias em direção a mudanças estruturais. Por outro lado, as principais atividades de Fuxin tendem a estar à mercê e limitadas pela interferência política de cima para baixo em um ambiente institucional que reforça essas características, o que resulta em persistência e extensão do caminho, com uma resiliência menos dinâmica e menor renovação econômica.

Em relação a outros países, Courvisanos, Jain e Mardaneh (2015) propõem estudo sobre padrões que emergem da capacidade adaptativa em quatro grupos funcionais distintos de regiões do governo local na Austrália, no que diz respeito à resiliência a choques em setores específicos. Avaliam, através de um modelo de ciclos adaptativos o impacto de dois grandes choques, uma seca de 13 anos e a Crise Financeira Global, em quatro grupos funcionais de regiões, usando dados do censo de 2001, 2006 e 2011. Em termos de resiliência, algumas regiões com indústrias fortes têm demonstrado capacidade de inovar e mudar para enfrentar choques que têm implicações econômicas graves. Outras regiões mostraram fraqueza nesse aspecto crucial do desenvolvimento econômico regional. Tratando sobre o caso da Austrália Ocidental, Plummer e McKenzie (2017) usam a mudança de renda durante um período de 30 anos para entender a resiliência de cada centro regional. As evidências mostraram que há variabilidade considerável entre os quatro centros, sendo que respondem em velocidades diferentes a choques e isso parece estar vinculado a condições locais e regionais específicas, mas em todos eles houve aumento da renda per capita e queda no desemprego durante o período.

Introduzindo a seção sobre casos da Europa, o trabalho de Xiao, Boschma e Andersson (2018a) explorou se a relação e a variedade, em termos de variedade relacionada e não relacionada, são importantes para a resiliência regional, pois esses conceitos estão intimamente ligados à abordagem evolutiva da resiliência. Análises mostram que as regiões europeias diferem amplamente em sua capacidade de criar novos caminhos para o setor após a crise de 2008. Como esperado, variedade relacionada e variedade não relacionada acabam sendo fatores cruciais que aumentam a probabilidade de uma região ser resiliente. Isso se aplica especialmente à variedade relacionada, que mostra um efeito positivo mais forte na resiliência regional.

Xiao, Boschma e Andersson (2018a) analisam o papel da especialização existente na explicação das variações na diversificação industrial, medida como a entrada de novas especializações em 173 regiões europeias durante o período 2004-2012. Demonstram que a probabilidade de uma nova especialização do setor se desenvolver em uma região está positivamente associada ao relacionamento do novo setor com os setores atuais da região. Porém, o efeito do relacionamento parece diminuir à medida que a capacidade de inovação de uma economia regional aumenta. Em sua análise, também em relação à crise de 2008, Sensier, Bristow e Healy (2016) revelam que, em nível nacional, apenas quatro economias, sendo a Alemanha, Luxemburgo, Polônia e Suíça, foram capazes de resistir ao choque econômico e manter, ou aumentar, seu nível de emprego. Apenas uma economia, a Polônia, foi capaz de resistir a uma queda no seu nível de PIB.

O estudo de Duschl (2016) analisa a turbulência na dinâmica firme das economias regionais da Alemanha durante os anos de crise econômica (2008-2010). Constatou-se que eventos extremos de crescimento são mais prováveis de ocorrer em regiões que apresentam um desempenho agregado mais 
forte e têm um número maior de funcionários com diploma universitário. Ainda sobre resiliência em regiões alemãs, Wink (2014) levanta em seu trabalho que, apesar de um grande declínio no PIB da Alemanha em 2009, o emprego diminuiu relativamente pouco. O sucesso em emergir da crise se refere à extensão do trabalho de curto prazo como um instrumento para manter a força de trabalho dentro das empresas e conectar períodos de menos trabalho com aumentos nas qualificações. Esse sucesso, no entanto, só foi possível porque se encaixava perfeitamente nas estratégias de ajuste de empresas industriais e sindicatos na Alemanha

Ao estudar as implicações de dois choques de mobilidade diferentes em duas regiões fronteiriças da Finlândia, geopoliticamente diferentes, o artigo ressaltou a importância da resiliência nas regiões fronteiriças. Sustenta-se o argumento de que as fronteiras abertas e a cooperação transfronteiriça constituem um recurso importante e aumentam a resiliência regional de várias maneiras, especialmente em termos de redes transfronteiriças, compartilhamento de informações e confiança. Em Tornio, a resiliência fronteiriça-regional é apoiada pela abertura da fronteira e pela cooperação transfronteiriça institucionalizada. Em Lappeenranta, existem muitas instituições de ensino e empresas relacionadas à biotecnologia que trazem crescimento econômico à região (PROKKOLA, 2019).

Bellini et al. (2017) tratam da contribuição do turismo para a resiliência econômica regional e questiona as maneiras pelas quais os formuladores de políticas regionais reconhecem a relevância do turismo e o integram às suas estratégias de desenvolvimento regional (e, em particular, às estratégias regionais de inovação). Navarro-Espigares, Martín-Segura e Hernández-Torres (2012) verificam se o peso relativo do setor de serviços na estrutura de produção das regiões espanholas tem uma influência decisiva na resiliência regional à crise econômica. Para tanto, usam uma série temporal de valor agregado bruto e emprego para as 17 regiões espanholas durante o período 1986-2009. Concluem que, tanto nas crises econômicas de 1992 quanto em 2008, as regiões intensivas em serviços mostraram maior resiliência, definida como resistência à perda de $\mathrm{VAB}$ e empregos derivados do impacto inicial da crise. Em termos de $\mathrm{VAB}$, as regiões com maior intensidade de setor de serviços sofreram uma recessão muito mais suave em 2009 e uma recuperação mais lenta em 2010. Portanto, o setor de serviços parece desempenhar um papel de amortecedor na resposta inicial à crise.

O trabalho de Antonietti e Boschma (2018) também investiga o papel do capital social na entrada de novas indústrias e nas saídas de indústrias existentes nas províncias italianas durante o período 20042010. Os resultados mostram que a ligação do capital social em uma região contribui positivamente para a entrada de novas indústrias, especialmente quando não estão relacionadas às especializações existentes na região. A ligação, e não a "importação" de capital social com novas habilidades, parece tornar as regiões resilientes em tempos de crise, reduzindo a probabilidade de saída, especialmente em setores não relacionados às especializações existentes nas regiões. Embora a ponte entre capital social tenha um efeito negativo na saída em tempos de prosperidade, ela não mostra mais esse efeito durante o período de crise. Os resultados sugerem que a ponte entre capital social perde seu papel de apoio em tempos de crise.

Plechero et al. (2020) destacam em seu trabalho como a trajetória específica de um Sistema Regional de Inovação molda distintamente os recursos das redes de inovação de uma região. A análise realizada revela que o desenvolvimento de redes de inovação nas duas regiões foi moldado por diferentes elementos regionais e que esses elementos influenciam indústrias recém-emergentes. Os elementos são: 1) a especialização industrial histórica da região, 2) as características do ambiente institucional e organizacional (também em termos de agência) da região e 3) as experiências dos processos de internacionalização na região.

Reforçando a importância das capacidades de inovação, Bristow e Healy (2018) ressaltam que os resultados de seu trabalho demonstram que a capacidade de inovação em uma região está fortemente relacionada à sua propensão a ser resiliente a choques econômicos. As regiões que se mostraram capazes de resistir à crise econômica de 2007-2008 na Europa tenderam a ter os mais altos níveis de capacidade e desempenho de inovação. Também demonstra que as regiões que foram menos capazes de responder à crise econômica apresentaram os níveis mais baixos de capacidade de inovação.

A síntese dos estudos e casos empíricos trazidos nesta seção auxiliam na compreensão da dicotomia existente entre a resiliência na União Europeia e em países ao redor do globo, especialmente nações periféricas. Questões como o desenvolvimento de novas habilidades e capacidades de inovação demonstram importância na construção de políticas, ainda mais se levarmos em conta a resiliência evolucionária. Frisa-se ainda que os estudos empíricos expostos contribuem no entendimento de possibilidades e de escolhas que o pesquisador pode fazer ao estudar resiliência regional.

\section{Considerações Finais}

Este artigo apresentou uma revisão sistêmica que agrega contribuições sobre as contribuições teóricas e empíricas advindas de pesquisas focadas na perspectiva evolucionária da resiliência regional, buscando principalmente possíveis contribuições do tema para países emergentes. A busca de pesquisas ocorreu 
através da base de publicações do Circle (Centre for Innovation, Research and Competence in the learning economy - Lund University), Periódicos CAPES e IDEAS RePEc sendo feita a seleção de 35 publicações.

O trabalho teve como objetivo revisar contribuições teóricas e empíricas, de forma não exaustiva, advindas de pesquisas focadas na perspectiva evolucionária da resiliência regional, buscando principalmente possíveis contribuições do tema para países emergentes e, dessa forma, o problema de pesquisa a ser respondido consistiu em: "Qual é a contribuição dos trabalhos selecionados para o entendimento das principais características (forma com que a resiliência é medida, conceito de região utilizado, entre outros) do conceito de resiliência regional evolucionária e de sua aplicação em regiões de países emergentes?". Após a realização da pesquisa, pode-se considerar que tanto o objetivo central como problema foram contemplados. De forma geral, os trabalhos avaliados concordam que esta pode ser definida como a capacidade permanente de um território de conceber e implantar novos recursos e capacidades que lhe permitam adaptar-se favoravelmente à dinâmica de transformação impulsionada pelas mudanças do ambiente. Da mesma forma, não há consenso sobre como ela deve ser mensurada, onde os trabalhos apresentam diferentes métodos e abordagens para tal. Valendo-se de perspectiva evolucionária para abordar a resiliência regional, os trabalhos afirmam que esta consiste na capacidade de uma região sustentar o desenvolvimento no longo prazo, sendo considerada tão importante quanto a capacidade de uma região responder positivamente a choques de curto prazo. Assim, a resiliência depende da capacidade das regiões lidarem com mudanças estruturais, criando novas trajetórias de crescimento para compensar processos inevitáveis de estagnação e declínio em sua economia regional.

Pode-se notar concentração de publicações, entre 2017 e 2020, correspondendo a 37,14\% dos trabalhos selecionados, evidenciando a pertinência de estudos nos últimos quatro anos sobre a resiliência de regiões e estratégias adotadas por estas. De fato, a relevância do tema se expressa através das constatações de diferentes trabalhos avaliados, onde a resiliência regional, principalmente em sua perspectiva evolucionária, defende a intervenção de políticas para promover a diversificação econômica e resiliência das regiões por meio de políticas personalizadas baseadas na relação entre as indústrias e na combinação de bases de conhecimento em um contexto de cooperação público-privada.

Ảinda, pôde-se resgatar estudos empíricos sobre a resiliência em diferentes territórios. Os casos brasileiros, chileno, indonésio e turco auxiliam a avaliar como o processo de resiliência ocorre em territórios diferentes dos que são tradicionalmente abordados na literatura, e apresentam casos que demonstram que o conceito de resiliência é importante também para economias emergentes. Contudo, nota-se uma alta concentração de estudos sobre a resiliência no continente europeu, principalmente no póscrise 2008, o que já era esperado.

Por fim, ressalta-se que a questão da adaptabilidade nas regiões parece ser essencial para a resiliência, onde a capacidade de inovação das regiões ou a capacidade de se reinventar continuamente é central para essa adaptabilidade. Pelos estudos, é possível compreender que economias resilientes tenham sistemas de inovação ágeis que promovam novas combinações de atividades, nas quais as organizações estejam dispostas a aceitar riscos e onde a adaptabilidade é incorporada ao comportamento dos atores de uma região.

\section{A reflection on evolutionary regional resilience for peripheral regions}

Abstract: This paper presents a literature review of research contributions on the evolutionary perspective of regional resilience, seeking contributions of the theme for peripheral regions. Thirty-five publications were selected from the CAPES, Circle (Lund University) and IDEAS RePEC databases. It waS identified that the concept of regional resilience goes beyond the capacity of a region to respond to economic shocks and should be able to sustain development in the long term, creating new growth paths to offset processes of economic stagnation and decline. The prominence that "innovation" and "knowledge" have in the discussion of evolutionary regional resilience is highlighted. Empirical studies on resilience in different regions are also reviewed, with an emphasis on emerging countries, where cases from Brazil, Chile, Indonesia and Turkey help identify that the concept needs to be explored further beyond the European continent.

Keywords: Evolutionary Regional Resilience; Innovation; Emerging Countries; Literature Review. 


\section{Referências bibliográficas}

ANTONIETTI, R.; BOSCHMA, R. Social capital, resilience and regional diversification in Italy. Papers in Evolutionary Economic Geography, v.18.04, 2018.2 Disponível em <http://econ.geo.uu.nl/peeg/peeg1804.pdf>. Acesso em 14 jul. 2020.

BELLINI, N. et al. Tourism and regional economic resilience from a policy perspective: lessons from smart specialization strategies in Europe, European Planning Studies, 2017. Disponível em <http://dx.doi.org/10.1080/09654313.2016.1273323 >. Acesso em 14 jul. 2020.

BOSCHMA, R. Towards an Evolutionary Perspective on Regional Resilience, Regional Studies, v. 49:5, p. 733-751, 2015. Disponível em <http://dx.doi.org/10.1080/00343404.2014.959481>. Acesso em 14 jul. 2020.

BRISTOW, G., HEALY, A. Innovation and regional economic resilience: an exploratory analysis. Ann Reg Sci, v. 60, p. 265-284, 2018. Disponível em <https://doi.org/10.1007/s00168-017-0841-6>. Acesso em 14 jul. 2020.

COENEN, L. et al. Advancing regional innovation systems: What does evolutionary economic geography bring to the policy table? Environment and Planning C: Politics and Space, v. 35, n. 4, p. 600-620, 2017. Disponível em <https://doi.org/10.1177/0263774X16646583>. Acesso em 14 jul. 2020.

COURVISANOS, J.; JAIN, A.; MARDANEH, K. K. Economic Resilience of Regions under Crises: A Study of the Australian Economy, Regional Studies, 2015. Disponível em <http://dx.doi.org/10.1080/00343404.2015.1034669>. Acesso em 14 jul. 2020.

CRESPO et al. Lock-in or lock-out? How structural properties of knowledge networks affect regional resilience. Journal of Economic Geography, v. 14, p. 199-219, 2014. Disponível em <doi:10.1093/jeg/lbt006>. Acesso em 14 jul. 2020.

DAWLEY, S. PIKE, A.; TOMANEY, J. Towards the Resilient Region?, Local Economy, v. 25:8, p. 650-667, 2010. Disponível em <http://dx.doi.org/10.1080/02690942.2010.533424>. Acesso em 14 jul. 2020.

DIDIER, T.; HEVIA, C.; SCHMUKLER, S. L. How resilient and countercyclical were emerging economies during the global financial crisis? Journal of International Money and Finance, v. 31, p. 2052-2077, 2012. Disponível em <https://doi.org/10.1016/j.jimonfin.2012.05.007>. Acesso em 14 jul. 2020.

DUSCHL, M. Firm dynamics and regional resilience: an empirical evolutionary perspective. Industrial and Corporate Change, v. 25, n. 5, p. 867-883, Outubro, 2016. Disponível em <doi: 10.1093/icc/dtw031>. Acesso em 14 jul. 2020.

ERAYDIN, A. Attributes and Characteristics of Regional Resilience: Defining and Measuring the Resilience of Turkish Regions, Regional Studies, 2015. Disponível em <http://dx.doi.org/10.1080/00343404.2015.1034672>. Acesso em 14 jul. 2020.

EVENHUIS, E. New directions in researching regional economic resilience and adaptation. Geography Compass.;11:e12333, 2017. Disponível em <https://doi.org/10.1111/gec3.12333>. Acesso em 14 jul. 2020.

EXTERCKOTER, R. K.; PUJOL, A. F. T.; SILVA, C. A. Anàlisi bibliomètrica del concepte de resiliència aplicat al desenvolupament regional. Documents d'Anàlisi Geogràfica, vol. 62/2, p. 275-298, 2016. Disponível em <http://dx.doi.org/10.5565/rev/dag.318>. Acesso em 14 jul. 2020.

GONÇALVES, C. Regiões, cidades e comunidades resilientes: novos princípios de desenvolvimento. urbe. Revista Brasileira de Gestão Urbana, maio/ago., v. 9(2), p. 371-385, 2017. Disponível em <https://www.scielo.br/pdf/urbe/v9n2/2175-3369-urbe-2175-3369009002AO15.pdf>. Acesso em 14 jul. 2020.

GONZÁLEZ-MUZZIO, C. El rol del lugar y el capital social en la resiliencia comunitaria posdesastre. Aproximaciones mediante un estudio de caso después del terremoto del 27/F. EURE, v.39, N. 117, p. 2548, maio, 2013. Disponível em <http://dx.doi.org/10.4067/S0250-71612013000200002>. Acesso em 14 jul. 2020.

GRUNSVEN, L.; HUTCHINSON, F. E. The evolution of the electronics industry on Batam Island (Riau Islands Province, Indonesia): an evolutionary trajectory contributing to regional resilience? GeoJourna/, v. 82, p. 475-492, 2017. Disponível em <https://doi.org/10.1007/s10708-015-9692-9>. Acesso em 14 jul. 2020.

HARRISON, A.; SEPÚLVEDA, C. Learning from Developing Country Experience: Growth and Economic Thought before and after the 2008-2009 Crisis. Comparative Economic Studies, v. 53, p. 431-453, 2011. Disponível em <https://doi.org/10.1057/ces.2011.6>. Acesso em 14 jul. 2020. 
HASSINK, R. Regional resilience: a promising concept to explain differences in regional economic adaptability? Cambridge Journal of Regions, Economy and Society, v. 3, p. 45-58, 2010. Disponível em <https://doi.org/10.1093/cjres/rsp033>. Acesso em 14 jul. 2020.

$\mathrm{HU}, \mathrm{X}$; Y YANG, C. Institutional change and divergente economic resilience: Path development of two resource-depleted cities in China. Urban Studies. p. 1-20, 2019. Disponível em <https://doi.org/10.1177/0042098018817223>. Acesso em 14 jul. 2020.

MACHADO, C. P. et al. System Dynamics and Learning Scenarios for Process Improvement and Regional Resilience: A Study in The Footwear Industry of Southern Brazil. Syst Pract Action Res, v. 32, p. 663686, 2019. Disponível em <https://doi.org/10.1007/s11213-019-9480-4>. Acesso em 14 jul. 2020.

MARTIN, R. Regional economic resilience, hysteresis and recessionary shocks. Journal of Economic Geography, v. 12, pp. 1-32, 2012. Disponível em <https://doi.org/10.1093/jeg/lbr019>. Acesso em 14 jul. 2020.

MARTIN, R.; SUNLEY, P. On the notion of regional economic resilience: conceptualization and explanation. Journal of Economic Geography, v. 15, p. 1-42, 2015. Disponível em <https://doi.org/10.1093/jeg/lbu015>. Acesso em 14 jul. 2020.

NAVARRO-ESPIGARRES, J. L.; MARTÍN-SEGURA, J. A.; HERNÁNDEZ-TORRES, E. The role of the service sector in regional economic resilience, The Service Industries Journal, v. 32:4, p. 571-590, 2012. Disponível em <http://dx.doi.org/10.1080/02642069.2011.596535>. Acesso em 14 jul. 2020.

NEFFKE, F. et al. How Do Regions Diversify over Time? Industry Relatedness and the Development of New Growth Paths in Regions. ECONOMIC GEOGRAPHY, v. 87(3), p. 237-265, 2011. Disponível em <http://dimetic.dime-eu.org/dimetic_files/Neffkeetal2011.pdf>. Acesso em 14 jul. 2020.

PENDALL, R.; FOSTER.; COWELL, M. Resilience and regions: building understanding of the metaphor. Resilience and regions: building understanding ofthe metaphor. Cambridge Journal of Regions, Economy and Society, v. 3, p. 71-84, 2010. Disponível em <https://doi.org/10.1093/cjres/rsp028>. Acesso em 14 jul. 2020.

PIKE, A.; DAWLEY, S.; TOMANEY, J. Resilience, adaptation and adaptability. Cambridge Journal of Regions, Economy and Society, v. 3, p. 59-70, 2010. Disponível em <https://doi.org/10.1093/cjres/rsq001>. Acesso em 14 jul. 2020.

PITTERI, S.; BRESCIANI, L. P. Resiliência regional nas perspectivas teórica e empírica: o caso do Polo Industrial de Cubatão, São Paulo. Revista Brasileira de Gestão e Desenvolvimento Regional, v. 10, n. $1, \quad$ p. 305-335, jan-abr, $2014 . \quad$ Disponível em <https://www.rbgdr.net/revista/index.php/rbgdr/article/view/1221>. Acesso em 14 jul. 2020.

PLECHERO, $M$ et al. Explaining the past, predicting the future: the influence of regional trajectories on innovation networks of new industries in emerging economies. Industry and Innovation, 2020. Disponível em <https://doi.org/10.1080/13662716.2020.1780419>. Acesso em 14 jul. 2020.

PLUMMER, P.; MCKENZIE, F. H. The evolution of regional capitals in Western Australia: empirical modelling and policy analysis 1984-2014, Rural Society, v. 26:3, p. 238-252, 2017. Disponível em <https://doi.org/10.1080/10371656.2017.1364483>. Acesso em 14 jul. 2020.

PROKKOLA, E. K. Border-regional resilience in EU internal and external border areas in Finland, European Planning Studies, v. 27:8, p. 1587-1606, 2019. Disponível em < https://doi.org/10.1080/09654313.2019.1595531>. Acesso em 14 jul. 2020.

SÁNCHEZ-ZAMORA, P.; GALLARDO-COBOS; CEÑA DELGADO, F. La noción de resiliencia en el análisis de las dinámicas territoriales rurales: Una aproximación al concepto mediante un enfoque territorial. Cuadernos de Desarrollo Rural, 13(77), p. 93-116, 2016. Disponível em <http://dx.doi.org/10.11144/Javeriana.cdr13-77.nrad>. Acesso em 14 jul. 2020.

SCHMIDT, V. K.; ZEN, . Desenvolvimento Regional e Resiliência de Cluster: uma proposta teórica. RPCA Revista Pensamento Contemporâneo em Administração, v. 13, n. 1, jan. - mar, 2019. Disponível em <https://doi.org/10.12712/rpca.v13i1.28142>. Acesso em 14 jul. 2020.

SENSIER, M.; BRISTOW, G.; HEALY, A. Measuring Regional Economic Resilience across Europe: Operationalizing a complex concept. Spatial Economic Analysis, 2016. Disponível em < http://dx.doi.org/10.1080/17421772.2016.1129435>. Acesso em 14 jul. 2020.

SILVA, C. A.; EXTERCKOTER, R. K. Resiliência: Contribuições e desafios para o estudo do desenvolvimento das regiões. GEOgraphia, Ano. 18, N037, 2016. Disponível em <https://doi.org/10.12712/rpca.v13i1.28142> . Acesso em 14 jul. 2020. 
SIMMIE, J.; MARTIN, R. The economic resilience of regions: towards na evolutionary approach. Cambridge Journal of Regions, Economy and Society, v. 3, p. 27-43, 2010. Disponível em < https://doi.org/10.1093/cjres/rsp029>. Acesso em 14 jul. 2020.

WINK, R. Regional Economic Resilience: European Experiences and Policy Issues. Raumforsch Raumordn, v. 72, p. 85-91, 2014. Disponível em <https://doi.org/10.1007/s13147-013-0265-4>. Acesso em 14 jul. 2020.

XIAO, X.; BOSCHMA, R.; ANDERSSON, M. Industrial Diversification in Europe: The Differentiated Role of Relatedness, Economic Geography, 94:5, p. 514-549, 2018a. Disponível em <https://doi.org/10.1080/00130095.2018.1444989>. Acesso em 14 jul. 2020.

XIAO, X.; BOSCHMA, R.; ANDERSSON, M. Resilience in the European Union: the effect of the 2008 crisis on the ability of regions in Europe to develop new industrial specializations, Industrial and Corporate Change, Vol. 27, No. 1, p. 15-47, 2018b. Disponível em <https://doi.org/10.1093/icc/dtx023>. Acesso em 14 jul. 2020. 
